\title{
EXPANSÃO DA EDUCAÇÃO INFANTIL E PROCESSOS DE EXCLUSÃO
}

\author{
FÚLVIAROSEMBERG \\ Fundação Carlos Chagas \\ Pontifícia Universidade Católica de São Paulo
}

\section{RESUMO}

O artigo analisa o processo de expansão da educação infantil (creches, pré-escolas e classes de alfabetização) que ocorreu durante o governo Geisel e seus desdobramentos atuais.

Utiliza como fontes, dados coletados, sistematizados e divulgados pelo IBGE e SEECMEC, além de documentos nacionais e de organismos intergovernamentais (UNICEF - Fundo das Nações Unidas para a Infância - e UNESCO).

Apoiando-se em correntes contemporâneas da Sociologia da Educação, de estudos de gênero e sobre relações raciais, o texto deslinda novos processos de exclusão criados pela política de "democratização"da educação infantil. Conclui refletindo sobre os sentidos de ações afirmativas e politicas para todos como estratégias de democratização da educação infantil.

EDUCAÇÃO INFANTIL - RELAÇÕES DE GÊNERO - RELAÇÕES RACIAIS - FORMAÇÃO DE PROFESSORES

\begin{abstract}
THE EXPANSION OF EARLY CHILDHOOD EDUCATION AND EXCLUSIONARY PROCESSES. This article analyzes the process of expanded early childhood education (day care centers, pre-schools and literacy classes) that took place during the Geisel government, and their present day developments. It utilizes date collected, systematized and disseminated by the IBGE and SEEC/MEC, as well as national documents and those of intergovernmental organizations (UNICEF and UNESCO). Supported in the latest currents of educational Sociology and studies of gender and race relations, the text details new exclusionary processes created by policies to "democratize" early childhood education. It concludes by reflecting on the meaning of affirmative action and policies for everyone as strategies for making early childhood education more democratic.
\end{abstract}

Texto preparado a partir do Relatório de Pesquisa A Expansão da Educação Infantil no Brasile Processos de Exclusão, que contou com a colaboração de Regina P. Pinto e o apoio da FAPESP e do SEDIAE-MEC. 
Nos últimos anos, vem se percebendo um maior interesse pelo tema da igualdade de oportunidades entre os sexos na educação. Seja no plano do conhecimento, seja no de ações em políticas educacionais, observa-se que a questão não constitui objeto de preocupação apenas de feministas, mas vem entrando nas agendas de balanços do século e metas para o próximo milênio.

Baudelot e Establet (1992. p.9) abrem extenso painel sobre o tema educação e mulheres com uma metáfora: "cada mês do século $X X$ contou tanto para a educação das mulheres quanto todos os séculos anteriores deste milênio. À luz destas mutações, as discussões dos séculos anteriores sobre a educação a ser dada às mulheres se assemelham a antecipações monstruosas, mesquinhas e desajeitadas: máquinas voadoras de Leonardo ao lado do Concorde".

Os autores resumem, nessa frase, a evidência de um amplo e constante acesso das mulheres à educação formal em todos os níveis de ensino, inclusive no superior, durante o século $X X$, resultando no fato de que encontramos, em inúmeros países, igualdade sexual de acesso e permanência na escola entre os estudantes. E mais: em vários países do mundo (inclusive no Brasil), as mulheres constituem maioria entre estudantes dos cursos secundário e superior. Nesse panorama educacional o que significaria, então, a igualdade de oportunidade entre os sexos?

Como em outras esferas da vida social, aqui também se observa uma clivagem entre países ricos e pobres. Para os países ricos, os temas que vêm mobilizando a preocupação de pesquisadores e administradores é a constatação da permanência de guetos sexuais nas carreiras escolares evidenciando uma bipolarização masculino-feminina entre exatas e humanidades. Associada a essa tendência, observa-se a preocupação com a permanência de uma ideologia sexista no interior da escola (materiais didáticos, currículo, relação professor-aluno, uso dos espaços, etc) e a busca de saídas para que a educação constitua uma instituição capaz de formar novos padrões de relações de gênero: preparando mais as mulheres para posições competitivas no mercado de trabalho; preparando os homens para assumirem mais a função de provedores de cuidado (Jensen, 1993).

Os países mais pobres têm sido exortados a garantirem o acesso das mulheres ao sistema educacional, em especial a diminuição do analfabetismo feminino, dado seu impacto perverso na vida produtiva e reprodutiva. Como venho mostrando em vários trabalhos (Rosemberg et al 1982; Rosemberg, Pinto, 1985; Rosemberg, 1994), a situação brasileira se assemelha à dos países ricos em patamar inferior. Isto é, quando se compara o acesso de mulheres ao de homens à educação formal, observam-se oportunidades e barreiras equivalentes associadas à origem econômica e ao pertencimento racial: mulheres e homens brancos de bom nível de renda familiar dispõem de boas e semelhantes oportunidades educacionais, ocorrendo na universidade a mesma formação de guetos sexuais das carreiras acadêmicas observada nos países ricos; mulheres e homens não brancos, contando com pequena renda familiar dispõem, igualmente, de péssimas condições educacionais. 
Esta particularidade do sistema educacional brasileiro — igualdade de oportunidades para os sexos no tocante ao acesso e permanência no sistema e intensa desigualdade associada ao pertencimento racial e à origem econômica — tem me levado a deslocar o eixo da reflexão e da busca de prioridades quando reflito sobre o tema da igualdade de oportunidades educacionais e as relações de gênero. Isso se traduz na pergunta: como as hierarquias de gênero interagem com as de raça e classe para produzirem um sistema educacional tão excludente quanto o brasileiro? $\bigcirc$ deslocamento de eixo tem me feito refletir sobre o sistema educacional simultaneamente como instância de formação de crianças, adolescentes, jovens e adultos e como mercado de trabalho (para serviçais, docentes e técnicos) que produzem e reproduzem relações de gênero.

No caso específico desta pesquisa, detive-me na análise do processo de exclusão de crianças negras e pobres resultante da política de expansão da educação infantil que vem ocorrendo no Brasil desde os anos 80'. Isto é, analisando a expansão da educação infantil no Brasil - que pode ser entendida como abertura do acesso ao sistema educacional para crianças com idade inferior a sete anos — deparei-me com dois processos discriminatórios simultâneos: o expressivo número de crianças retidas no pré-escolar ao invés de freqüentarem o ensino fundamental em que deveriam estar por direito (número que é mais expressivo para crianças negras ${ }^{2}$, residindo no Nordeste); aumento significativo do número de professoras leigas (sem qualificação educacional compatível) arcando com a expansão das matrículas no pré-escolar. Entender este processo de articulação entre hierarquia de raça e de gênero no sistema educacional tem-me feito procurar integrar aportes de teorias constituídas no campo da Sociologia da Educação sobre igualdade de oportunidades, à produção feminista que incorpora o conceito de gênero como categoria analítica e à emergente literatura que vem mapeando a discriminação racial na sociedade brasileira. Esses diferentes aportes teóricos compartilham a concepção de que dominação/subordinação e contradições estão no cerne da dinâmica social.

I.Dentre os teóricos da Sociologia da Educação, em primeiro lugar destaco o trabaIho de Petitat (1994) que, ao estudar o processo de democratização da educação secundária francesa, conclui:

I. As fontes para esta análise foram processamentos especiais de dados coletados pelo IBGE (PNADs e Censos) e pelo Departamento de Estatística do MEC (SEEC/MEC) além de documentos organizados na base de dados sobre criança pequena da Biblioteca Anna Maria Poppovic (Fundação Carlos Chagas) e daqueles coletados (com o auxilio de Maria Thereza Montenegro e Lívia Maria Fraga Vieira) nas bibliotecas da UNICEF em Brasília, Bogotá e Nova York e da UNESCO em Paris. Uma discussão sobre a qualidade das estatísticas referentes à educação infantil disponíveis no Brasil e a validade dos indicadores usados (especialmente taxas de cobertura) será publicada no artigo "O estado dos dados para avaliar políticas de educação infantil" (Rosemberg, 1999). Uma versão preliminar das transformações da política de educação infantil na UNESCO a partir de sua criação pode ser encontrada em Rosemberg (1998).

2. Denomina-se raça negra, neste trabalho, o contingente de pessoas que se declaram pretas e pardas. As questões complexas sobre classificação racial no Brasil (com base na aparência e não na origem) foi objeto de discussão no texto completo que originou este artigo (Rosemberg, 1997a). 
- A democratização de um nível de estudos deve ser sempre analisada em relação às diferenciações e às novas hierarquias de ensino que se inscrevem neste mesmo nível;

- Conseqüentemente, estas novas hierarquias se encaixam segundo uma nova definição nos estudos anteriores, os quais também se encontram em vias de diferenciação (...)

- Qualquer apreciação da democratização dos estudos é ao mesmo tempo uma apreciação destas reacomodações hierárquicas. A avaliação da redução da desigualdade de oportunidades propõe problemas complexos devido à evolução das hierarquias escolares. A este problema acrescenta-se o da evolução das próprias hierarquias sociais. (Petitat, 1994. p.230-I)

Petitat ( 1994) não avança na compreensão das hierarquias de gênero e raça, questão que vem sendo aprofundada nos trabalhos dos chamados teóricos da resistência (Apple, Enguita, Giroux, Anyon) que, rompendo com o determinismo estruturalista, centram também "a atenção nos processos culturais pelos quais os sujeitos do processo educacional percebem, mudam e transformam os significados e os fins da instituição enquadrando-os nos determinantes das subculturas de classe, gênero e raça nas quais estão inseridos seus protagonistas" (Enguita, 1989. p. 155-6).

A contribuição destes teóricos para se compreender a dinâmica social no geral, e na educação mais especificamente, pode ser resumida em três eixos convergentes: a atenção simultânea às esferas econômica, política e cultural sem redução de uma à outra; a compreensão de que a dinâmica social resulta de um jogo complexo de contradições de classe, gênero, raça e idade nas diferentes esferas; a concepção de um sujeito histórico ativo, acomodando-se e resistindo às barreiras que a sociedade interpõe à realização de suas necessidades, de seus projetos e desejos, o que envolve o enfrentamento de contradições nas três esferas (econômica, política e cultural) e nas diferentes dinâmicas de classe, gênero, raça e idade.

No Brasil, a busca de compreensão simultânea das hierarquias de gênero, raça e classe tem se baseado, muitas vezes, em modelo cumulativo, esperando-se uma associação linear das diferentes formas de subordinação. Esse modelo associativo não dá conta, porém, da complexidade e das contradições observadas nas instituiç̧ões educacionais onde as dinâmicas de gênero, raça e classe não são redutíveis umas às outras, evidenciando, ao contrário, um movimento não sincrônico. $\bigcirc$ conceito de não sincronia, introduzido por Emily Hicks ( $\mid 98 \mathrm{I}$ ), possibilita apreender melhor o jogo de conflitos, tensões e contradições inter e intra-institucionais que se observa entre hierarquias de gênero, raça e classe: "indivíduos (ou grupos) em suas relações com os sistemas político e econômico não compartilham da mesma consciência ou das mesmas necessidades no mesmo momento" (Hicks, 1981. p.22I). Isso significa que a interseção dessas relações pode levar a rupturas, descontinuidades, alterações ou incremento do impacto original das dinâmicas de raça, classe ou gênero em dado contexto social ou institucional. Nem as pessoas individualmente, nem os movimentos sociais 
desenvolvem em perfeita sincronia consciência de classe, gênero e raça. Por exemplo, a busca de superar subordinações de classe pode ignorar ou mesmo apoiar-se em subordinações de gênero e raça. Intervenções igualitárias podem ter impactos diversos nos diferentes segmentos sociais ${ }^{3}$.

Nesta pesquisa, mostrarei, adiante, como a expansão da educação infantil brasileira, apoiada no argumento da igualdade de oportunidades para crianças das classes populares no ensino fundamental, baseou-se na ideologia das aptidões naturais femininas para o exercício da função docente, que levou a um novo processo de exclusão de crianças pobres e negras, além de discriminação de mulheres adultas das classes populares.

2.Dentre as diferentes correntes feministas contemporâneas, venho encontrando afınidades, nos planos político e teórico, com os trabalhos de Maria Jesus Izquierdo, estudiosa catalã.

Izquierdo considera que o preconceito diante das diferentes capacidades das mulheres e dos homens (que conceitua como sendo sexismo) é acompanhado de uma concepção hierárquica de dominação do gênero masculino sobre o feminino.

As capacidades específicas das fêmeas têm a ver com atividades de gênero consideradas de segunda ordem para o funcionamento e desenvolvimento da sociedade, precisamente as relativas à produção da vida humana. As atividades específicas dos machos, relativas à produção e administração das coisas, consideram-se fundamentais, de primeira ordem. A partir dessa valorização distinta do masculino e do feminino constrói-se uma hierarquia dos gêneros. A hierarquia dos gêneros conduz ao estabelecimento de relações de dominação/ subordinação entre o gênero masculino e o feminino, independentemente de qual seja o sexo das pessoas que ocupam os espaços sociais de gênero, nas relações de gênero. A título de exemplo, a prática da enfermagem é uma atividade de gênero feminino e a da medicina de gênero masculino. Do ponto de vista das hierarquias, a medicina ocupa um posto superior ao da enfermagem inclusive quando é uma mulher quem exerce a medicina e um homem quem exerce a enfermagem, porque, acima de tudo, as relações de gênero são relações de caráter hierárquico. (1991. p.82, grifos da autora)

A educação infantil — tanto na vertente creche quanto na vertente pré-escola — é uma atividade historicamente vinculada à "produção humana" e considerada de gênero feminino, tendo, além disso, sido sempre exercida por mulheres, diferentemente de outros níveis educacionais, que podem estar mais ou menos associados à produção da vida e de riquezas. Isto é, diferentemente de outras formas de ensino, que eram ocupações masculinas e se feminizaram, as atividades do jardim-da-infância e de assistência social voltadas à infância pobre iniciaram-se já como vocações femininas no século $X I X$, tendo ideais diferentes das ocupações masculinas que evoluíam no mesmo período. Nos EUA,

3. Mariano Enguita (1996) apresentou na Conferência de Abertura da XIX Reunião Anual da ANPEd instigante estudo sobre "Os desiguais resultados das políticas igualitárias" nas perspectivas de classe, gênero e etnia na educação. Naquela conferência, Enguita apontou os impactos da diacronia (termo que não usa) no sistema educacional espanhol: "Poderemos dizer, então, que os trabalhadores foram incorporados à escola burguesa, as mulheres à dos homens e os ciganos à dos payos" (p.9). 
(...) diferentemente das ocupações masculinas, que basearam sua qualificação e competência no treino e domínio de conhecimentos profissionais e habilidades técnicas, supostamente não relacionadas a atributos [biológicos] masculinos, trabalhadores nesta área de assistência à infância basearam suas qualificações em sua capacidade de amar as crianças e no treino em técnicas educacionais de cuidar de crianças explicitamente associadas a tipos de comportamentos [ou natureza] femininos. (Beatty, 1989. p.36)

Analisando o impacto desta especificidade, Barbara Beatty conclui:

(...) esta ideologia da vocação espiritual e emocional e o acesso relativamente aberto à educação infantil como ocupação teve resultados tanto negativos quanto positivos. (...) De um lado fez com que a educação infantil fosse uma ocupação atraente para muitas mulheres (...) por causa de sua informalidade e o apelo de poder se expressar e ser paga para cuidar. E com nenhum, ou quase nenhum treinamento específico, um número significativo de mulheres tornaram-se professoras de educação infantil simplesmente em virtude de seu sexo e do amor devotado às crianças associados ao gênero feminino. Esta facilidade de acesso beneficiou, também, mulheres de origem econômica inferior para as quais ensinar crianças pequenas constituía uma possibilidade de ascensão social. (1989. p.47).

Beatty assinala que, por outro lado, o fato de não ter sido necessária uma formação técnica/profissional específica desvalorizou o salário e o prestígio dessa ocupação.

No Brasil, o desprestígio da educação infantil tem origem próxima e distinta daquela evidenciada nos EUA por Beatty (1989). A creche não foi pensada para a "produção" de qualquer ser humano, mas dos filhos recém-libertos de mães escravas. $\bigcirc$ primeiro texto sobre creche de que se tem notícia no país foi publicado na Revista $A$ Mãi de Família, em 1879, por um médico afeto à roda dos expostos, Dr. Vinelli, que assim se expressou:

A creche é um estabelecimento de beneficência que tem por fim receber, todos os dias úteis e durante as horas de trabalho, as crianças de dois anos de idade para baixo, cujas mães são pobres, de boa conduta e trabalham fora de seu domicilio.

$[\ldots]$

No Brasil ainda não existe a creche; entretanto, sua necessidade me parece palpitante, sobretudo, nas atuais condições em que se acha o nosso país depois da moralizadora e humanitária lei de 28 de setembro de I87। , em virtude da qual nele não nasce mais um escravo. Agora que, graças a iniciativa do governo e também dos particulares em não pequena escala, com a emancipação da escravatura vai desaparecendo o vergonhoso estigma que a civilização repele e abomina, um grande número de mulheres que quando escravas trabalhavam para seus senhores que por sua vez eram obrigados a the dar alimentação, domićlio e vestuário, a cuidar de sua saúde e da de seus filhos, ganhando liberdade, vêem-se não poucas vezes abandonadas com filhos pequenos, que ainda mamam, sem ter quem os sustente, na indeclinável e urgente necessidade de procurarem pelo trabalho, ganhar os meios da própria subsistência e de seus filhos e em muitos casos, sem poderem consegui-lo por que a isso as impedem como obstáculo insuperável os filhos pequenos, que elas não tem a quem confiar e cuja tenra idade não Ihes permite mandá-los para a escola. Não há senhora alguma dona de 
casa, que ignore a extrema dificuldade senão impossibilidade que encontra uma criada, por exemplo, em alugar-se quando traz consigo um filho a quem amamenta. [Com a criação da creche] a mãe já não encontra dificuldade em empregar-se e pode então tranqülla dedicar-se ao trabalho que Ihe há de trazer os meios de manter-se. (Apud Civiletti, 1991. p.36-7)

Percebe-se uma trajetória quase que linear entre a concepção originada no século $\mathrm{XIX}$ e a vertente da educação infantil que vem sendo destinada a crianças pobres e negras.

3.Podem-se distinguir três grandes correntes que caracterizam o pensamento social brasileiro sobre as relações raciais (Rosemberg, Pinto, 1989).

A primeira delas, ligada originalmente a Gilberto Freyre, postula a existência de uma democracia racial.

A segunda, liderada por Florestan Fernandes, desnuda uma profunda desigualdade entre os segmentos branco e negro da população e interpreta as relações raciais no período pós-abolicionista como resquícios do Antigo Regime, incompatíveis com a nova ordem social que se configura numa sociedade competitiva e de classes. Portanto, apesar de esta corrente reconhecer a existência de desigualdades raciais, assume uma perspectiva otimista pois, de acordo com seu enfoque, a discriminação racial tenderia a desaparecer com o desenvolvimento da industrialização. Tal corrente influenciou marcadamente o pensamento educacional brasileiro que, ao reconhecer a concentração maciça do alunado negro nas camadas mais pobres da população, tende a identificar as dificuldades interpostas à escolaridade dos negros com os problemas enfrentados pela pobreza, não considerando a especificidade da origem racial.

A terceira corrente, representada por uma "nova geração de cientistas sociais" - tendo em Carlos Hasenbalg (1979) um de seus pioneiros - e pelo movimento negro contemporâneo (Skidmore, 199I), analisa as articulações entre raça e classe de uma outra perspectiva. Embora, sem negar que o destino da população negra - que Hasenbalg reconhece vinculada aos grupos e às classes sociais subordinadas - esteja associado "à evolução política e estrutural da sociedade brasileira", o autor pretende verificar, com maior acuidade, o peso da raça na análise das desigualdades entre a população branca e a negra. Diz ele:

Sem dúvida alguma a grande maioria dos negros ${ }^{4}$ e mulatos no Brasil é exposta aos mesmos mecanismos de dominação de classe que afetam outros grupos subordinados. Mas, além disto, as pessoas de cor sofrem uma desqualificação peculiar e desvantagens competitivas que provêm de sua condição racial. (1979. p. 20)

Para Hasenbalg, tais desigualdades não derivam apenas das diferenças observáveis no ponto de partida de ambas as populações, mas são devidas, principalmente, às oportunidades desiguais de ascensão após a abolição da escravidão e do racismo contemporâneo enfrentado pela população negra. Dentre as circunstâncias que contribuíram para este desequilíbrio,

4. $\bigcirc$ autor denomina negro o contingente da população que se autoclassifica como sendo de cor preta. 
destaca (sem porém esgotar toda explicação) a política de imigração impregnada de "matizes racistas" que resultou na marginalização dos negros e reforçou o padrão de distribuição regional dos dois grupos raciais: os negros se concentraram nas regiões economicamente menos desenvolvidas (principalmente no Nordeste), onde as oportunidades ocupacionais e educacionais eram muito limitadas; e os brancos, na região Sudeste ou Brasil desenvolvido. De acordo com tal perspectiva, qualquer análise sobre essas desigualdades tem de levar em conta também as diferenças regionais e o grau de concentração da população branca e negra nas regiões fisiográficas.

Veremos, no decorrer do trabalho, como uma política de educação infantil para todos, construída a partir de um modelo, com baixo investimento, sustentado pela disponibilidade de mão-de-obra feminina sem qualificação compatível com a função docente e declarando-se como medida para equalizar as oportunidades de acesso ao ensino fundamental nas regiões mais pobres do país (estados do Norte e Nordeste), redundou em novo processo de exclusão de crianças negras do sistema educacional e discriminação de mulheres no mercado de trabalho.

\section{A EXPANSÃO DA EDUCAÇÃO INFANTIL NO BRASIL}

O Brasil das últimas décadas apresenta um perfil sociodemográfico compatível com a expansão da demanda por educação infantil (Tabela I). A urbanização intensa, a participação crescente das mulheres no mercado de trabalho, a queda dos índices de mortalidade infantil e de fecundidade anunciavam, já no final da década de setenta, que estavam constituídas as bases sociodemográficas geralmente associadas à expansão da educação infantil (Cochran, 1993; Rosemberg, 1997a).

TABELA I

INDICADORES SOCIODEMOGRÁFICOS SELECIONADOS BRASIL, I 970, 80 E 90/9।

\begin{tabular}{lccccc}
\hline \multicolumn{1}{c}{ INDICADORES } & \multicolumn{5}{c}{ ANOS } \\
& 1970 & 1980 & 1990 & $/$ & |99|* \\
\hline Taxa de crianças de 0 a 4 anos na população & 14,8 & 13,8 & - & 11,3 \\
Taxa de população urbana & 55,9 & 67,6 & - & 75,6 \\
Taxa de atividade das mulheres tendo I0 anos ou mais & $18,2 *$ & 26,6 & 39,2 & - \\
Taxa de mulheres chefes de domićlio & & $15,6 *$ & - & $\mid 8,1$ \\
Taxa de fecundidade & $6,0 *$ & 4,0 & 2,7 & - \\
Taxa de mortalidade infantil & $89,5 *$ & 69,1 & 49,7 & - \\
\hline
\end{tabular}

Fontes: * Barroso (1982) para as taxas assinaladas com asterisco (*).

Censos Demográficos 80 e 91 e PNAD 90 apud Anuário Estatístico do Brasil 1994 (FIBGE, 1994) para as demais taxas.

Durante os governos militares, o Estado formulou uma política de intensa expansão da oferta de vagas, configurando à educação infantil um perfil de atendimento de massa, principalmente por meio de programas implantados pelos extintos Movimento Brasileiro de 
Alfabetização - MOBRAL e Legião Brasileira de Assistência - LBA. Apoiado numa concepção de educação compensatória, preparando crianças consideradas carentes para o ingresso no ensino fundamental, esse modelo sofreu, posteriormente, o impacto de novas idéias sobre educação infantil veiculadas pelos movimentos sociais das décadas de setenta e oitenta (o movimento de mulheres e o movimento pelos direitos das crianças e dos adolescentes), redundando em propostas avançadas para a Constituição de 1988, mas que não foram implantadas $^{5}$. O modelo adotado foi nitidamente influenciado, no início, por propostas elaboradas e divulgadas pelas organizações intergovernamentais, em especial a UNICEF e a UNESCO (Kramer, 1995; Vilarinho, 1987; Rosemberg, 1997b).

Até o início da década de setenta, o modelo de educação pré-escolar - na verdade, denominada pré-primária - perseguido pela administração educacional, divergia do modelo da creche destinada aos pobres e alinhavam-se às recomendações emanadas da XXVI Conferência Internacional da Instrução Pública da UNESCO, de 196I (UNESCO, 196I)6. Este documento enfatizava o caráter essencialmente educativo da pré-escola, que deveria adotar um modelo formal, adequando-se, antes de tudo, à idade da criança. Recomendava-se um atendimento de preferência público e, nesse caso, gratuito. $\bigcirc$ corpo docente deveria eqüivaler, na sua formação e remuneração, ao da escola primária. A relação adulto-criança não deveria ultrapassar I/20 e os espaços físicos - na sua dimensão, luminosidade, higiene e limpeza deveriam adequar-se às características da idade (UNESCO, 196I). Era esse o modelo praticado em pequena escala no país e aquele desejado por técnicos das Secretarias Estaduais de Educação que já haviam implantado redes de pré-escola, considerado, porém, por alguns como um atendimento "elitista" diante do novo projeto de extensão da cobertura, visando compensar carências de populações empobrecidas e prepará-las para o ingresso no ensino fundamental.

Durante as décadas de cinqüenta e sessenta, em plena Guerra Fria, a UNICEF vinha lançando as bases conceituais que constituíram o modelo de educação infantil a baixo custo propagado em diversos países subdesenvolvidos, inclusive no Brasil. Dentre as diversas orientações do período (Black, 1986; Egger, 1985) destacam-se três: a ênfase na participação da comunidade para implantação da política social destinada à infância pobre; a estratégia de atuar junto aos governos nacionais; a entrada da UNICEF na esfera da educação. Essa nova estratégia acarretou a expansão da ação da UNICEF para além do binômio saúde-nutrição que constituíra a prioridade daquela instituição até então, envolvendo-se, de início, em projetos educacionais e, posteriormente, voltando sua atenção para a "transmissão de valores às

5. Apesar de mobilizado no processo constituinte, o movimento negro defendia uma agenda educacional mais voltada para o ensino fundamental e níveis superiores, negligenciando-se da educação infantil. Entendo esta prioridade como decorrente de seu envolvimento primeiro com questões ideológicas relacionadas ao resgate da identidade negra, por meio, principalmente, da reformulação de conteúdos curriculares.

6. Este modelo de educação infantil inspirava-se diretamente nas écoles maternelles francesas. A inspiração foi intermediada, no período, pela Organização Mundial de Educação Pré-escolar - OMEP, ONG credenciada junto à UNESCO, que havia designado Mme. Herbenière-Lebert, inspetora geral das escolas maternais francesas, como sua assessora junto àquele organismo internacional (Rosemberg, 1998). 
novas gerações" até ocupar-se da criança como um todo. É nesta caminhada globalizante que a UNICEF voltou sua atenção para a educação pré-escolar, e investiu em terreno que, até então, era de competência da UNESCO (Myers, s/d). Ou seja, uma instituição que vinha atuando na área da assistência à infância, borra os contornos de sua competência e entra em seara alheia, a educação escolar, da alçada da UNESCO.

A elaboração e divulgação das novas propostas da UNICEF para a infância e a juventude ocorreram por meio de estudos, publicações, seminários, conferências internacionais ou regionais, reuniões da comissão executiva e atuação de seus técnicos que assessoravam diretamente instituições nacionais na elaboração de planos setoriais a serem incorporados pelos nacionais. Para a América Latina, destaca-se a Conferência de Santiago do Chile realizada em 1965. A Conferência recomendava que os planos nacionais de desenvolvimento contemplassem as necessidades globais da infância e da juventude, inclusive da criança préescolar, que previssem mecanismos de integração interministerial e a utilização das energias de grupos e movimentos (a comunidade). Esses elementos aperfeiçoados constituíram as bases das novas propostas de educação pré-escolar em massa no Brasil (UNICEF, 1968. p.87-9).

O Brasil foi representado nessa Conferência pelo Departamento Nacional da Criança DNCr - que também esteve presente na reunião da Comissão Executiva da UNICEF de 1965, quando se discutiu "Como proteger em massa pré-escolares". O DNCr preparou, para apresentar na reunião, um diagnóstico sobre o pré-escolar no Brasil e dela trouxe as idéias que guiaram a elaboração do Plano de Assistência ao Pré-escolar (Brasil, 1967), apresentado no I Congresso Interamericano de Educação Pré-escolar, realizado no Rio de Janeiro em 1968. Nesse documento estão presentes as orientações que guiaram as propostas governamentais de pré-escola de massa elaboradas no Brasil durante a década de setenta e parte da de oitenta.

O plano do DNCr de 1967 é explícito ao especificar que se trata de uma política de assistência ao pré-escolar e não de uma política educacional para a pré-escola, especificidade que se perde, porém, em planos subseqüentes que se autodenominaram programas nacionais de educação pré-escolar ${ }^{7}$. O documento do DNCr é sóbrio, sinalizando tratar-se de um plano de emergência, sobriedade que também se perde em propostas subseqüentes: nas décadas de setenta e oitenta o qualificativo "emergência" foi substituído por "alternativo", "não convencional", "informal" em oposição à educação "tradicional", "institucional" ou "formal". Aquilo que, inicialmente, era determinado pela falta de recursos passou a ser "teorizado" tornando-se, muitas vezes, nos textos, um ideal a ser perseguido, um modelo a ser imitado. Esse modelo foi propagado no território nacional para o atendimento público ou subvencionado com verbas públicas. $\bigcirc$ antigo modelo, considerado agora elitista, ficou reservado ao sistema privado usado pelos estratos médios da população.

7. A mudança de terminologia, aparentemente universal, de educação pré-primária para educação pré-escolar (algo que necessita ser mais bem compreendido pela História da Educação), acarretou transformações em sua associação a outros vocábulos. A expressão pré-primária foi sempre associada a escola ou ensino e nunca a criança. O vocabulário pré-escolar passou a designar tanto uma etapa da vida, quanto um nível educacional. 
Esse modelo de programas de massa para a pré-escola vinha também sendo gestado pela UNESCO ao final dos anos sessenta. Myers (s/d) transcreve trechos de um documento sobre o pré-escolar, elaborado conjuntamente pela UNESCO e pela UNICEF, datado de 1968, o qual, após insistir na necessidade de uma atenção especial à criança pequena e destacar a dificuldade de implantação de programas formais nos países em desenvolvimento, sugere: "uma solução possível que alguns países em desenvolvimento estão adotando é a criação de classes de pré-primário anexas às escolas primárias, segundo um modelo simplificado e, conseqüentemente, mais barato que os jardins de infância" (Myers, s/d, p.5). No início da década de setenta, a chamada Comissão Faure ${ }^{8}$ sistematizava uma nova concepção de educação infantil: como primeira etapa da educação permanente. Uma "pré-condição essencial para qualquer política educacional e cultural", a educação infantil deveria, portanto, ampliar sua cobertura. A forma sugerida para a extensão de vagas seria com soluções de baixo custo, não formais e parcialmente assumidas pelas famílias.

Trata-se de organizar-se, de maneira ágil e livre, a educação das crianças em idade préescolar (a partir dos dois ou três anos), procurando os melhores meios para associar a família e a comunidade local nas tarefas e nos gastos. Trata-se, também, de utilizar os meios modernos de comunicação, que podem prestar grandes serviços principalmente às crianças que vivem em ambientes de escassa impregnação cultural. (Faure, 1972. p.21 $)^{9}$

Deve-se notar que esse modelo, ao fazer apelo à comunidade para participar da implantação baseia-se nas "aptidões inatas" das mulheres para cuidarem de crianças pequenas fortalecendo e legitimando duas trajetórias de educação infantil: uma profissional, baseada em formação educacional do corpo docente, envolvendo espaços e equipamentos específicos; outra doméstica-familiar, apoiando-se nos recursos disponíveis na "comunidade" e não na profissionalização das educadoras (que receberiam apenas capacitação esporádica) ${ }^{10}$.

No MEC, os primeiros sinais da gestação de um novo modelo de educação préescolar de massa foram emitidos pelo Conselho Federal de Educação - CFE -, no início da década de setenta, por meio de pareceres e recomendações. Esses pareceres, ao cobrirem lacunas da lei 5.692/7I, evidenciam uma absorção das idéias da educação compensatória

8. As recomendações formuladas por esta comissão - Comissão Internacional pelo Desenvolvimento da Educação - foram acolhidas pelas Conferências Gerais da UNESCO (UNESCO, 1988).

9. Esta mudança na concepção de educação infantil nos documentos produzidos na ou pela UNESCO foi acompanhada de uma mudança no corpo de assessores dessa organização. Nomes como Wallon, Piaget, Zazzo e Wall, que apareciam em publicações e seminários, foram sendo substituídos por especialistas em planejamento e economia (Rosemberg, 1998).

10. O Brasil não foi o único país a adotar um modelo de massa a baixo custo apoiado em "habilidades naturais" das mulheres para cuidar de criança pequena. Durante os anos setenta e oitenta, a UNICEF e o Banco Mundial divulgaram pelo mundo o programa de creches domiciliares que se transformou no Programa nacional de expansão da educação infantil na Colômbia (a partir de Cochran, 1993). O sexismo deste modelo é ainda mais acentuado que o daquele implantado no Brasil (Rosemberg, 1986). 
(Ferrari, 1982) e do novo modelo de pré-escolar de massa. A similaridade entre as propostas da UNICEF e da UNESCO e a que foi se gestando no MEC por meio de pareceres é evidente. "Trata-se de implementar uma verdadeira política de educação compensatória que vise equalizar as oportunidades educacionais" (Parecer CFE 20 I 8/74), pela adoção de modelos não-convencionais, procurando mobilizar toda a comunidade (Indicação CFE 45/74).

As recomendações sobre pré-escolar da Comissão Faure aparecem como epígrafe, em 1975, ao programa Educação Pré-Escolar: Uma Nova Perspectiva nacional (Brasil, 1975), elaborado pelo então setor de Educação Pré-Escolar do MEC. Esse programa absorveu, na sua totalidade, as recomendações da UNICEF e da UNESCO: educação, nutrição e saúde deveriam ser atendidas de forma integrada; utilização de espaços físicos disponíveis (ou ociosos) na comunidade; a família e a comunidade fariam parte integrante das atividades de educação pré-escolar, objetivando despertar a consciência sobre a importância da idade préescolar e o barateamento dos programas; os meios de comunicação de massa deveriam ser utilizados para atingir populações distanciadas do espaço escolar.

A função de assistência foi formalmente assumida na previsão das áreas definidas como prioritárias: periferias das cidades com mais de 20 mil habitantes e áreas que apresentassem taxas de mortalidade infantil elevadas, principalmente no Nordeste.

O plano do MEC era extremamente vago quanto aos recursos orçamentários: "além dos recursos orçamentários do MEC, previstos a partir de 1976, há o recurso do Fundo de Assistência Social, administrado pelo Conselho de Desenvolvimento Social - CDS -, composto pelos Ministros de Estado da área social e o recurso de financiamento externo" (Brasil, 1975. p.30).

A proposta do MEC de 1975, com alguns ajustes periféricos, tornou-se o modelo nacional público de atenção ao pré-escolar extrapolando os limites das regiões consideradas, inicialmente, como prioritárias.

Apesar de ter formulado um programa nacional de educação pré-escolar de massa, não foi o MEC que conseguiu implantá-lo na década de setenta, mas sim a LBA, com o Projeto Casulo. Lançando em 1977, o projeto rapidamente se expandiu, ultrapassando a meta prefixada de atender a 70 mil crianças no ano de implantação. Atuando de forma indireta, repassando recursos a instituições privadas e prefeituras, a LBA conseguiu, então, implantar um programa nacional antes do MEC. Não havia resistências eqüivalentes às enfrentadas pelo MEC, principalmente por se tratar de um órgão de assistência, que já desenvolvia um discurso e uma prática de participação da comunidade e que dispunha de uma rede capilar de serviços, repassando verbas diretamente às instituições comunitárias, sem necessidade de intermediação das instâncias administrativas estaduais e municipais.

Para difundir o Projeto Casulo durante o governo do Gal. Geisel, a LBA usou o discurso da prevenção à desordem social decorrente da existência de "bolsões de ressentimento", isto é, das populações empobrecidas principalmente nas periferias urbanas, passíveis de ameaçarem a segurança nacional. No contexto da Guerra Fria, o Projeto Casulo, como a política social daquele governo, incorporou o discurso da Doutrina de Segurança Nacional (Rosemberg, 1997b), da mesma forma que a matriz político-ideológica dos programas de 
desenvolvimento de comunidade, no plano internacional, fora inspirada pelo mesmo discurso no contexto da Guerra Fria (Amman, 1982).

A estratégia usada pela LBA para expansão do número de vagas foi peculiar: baseouse, essencialmente, na diminuição do per capita mensal repassado às entidades beneficiadas. Desse modo, após uma rápida expansão inicial baseada em recursos compatíveis, o aumento de vagas ocorreu às expensas da diminuição do custeio da criança (Lima, 1994).

Foi então por intermédio do MOBRAL (órgão ameaçado de extinção e que fora criado para a alfabetização de jovens e adultos) que o MEC lançou e implantou, em | 981, o Programa Nacional de Educação Pré-escolar.

O MOBRAL entrou no âmbito do pré-escolar adotando, e explicitando, as propostas da UNICEF para esta faixa de idade " . Diferentemente do que ocorrera antes, desta vez, os recursos orçamentários e técnicos, provenientes da fundação MOBRAL, e o repasse de verbas por meio de convênios causaram um impacto na extensão de vagas, alterando o modelo de funcionamento da educação pré-escolar.

Ambas as instituições LBA e MEC adotaram modelos convergentes de educação infantil. Assim, creches e pré-escolas, instituições distintas até o início dos anos setenta, pouco ou nada se diferenciaram: visando a compensação de carências, subordinaram a educação à assistência, definiram as mesmas zonas e regiões prioritárias para intervenção (região Nordeste e periferias urbanas), e o modelo pedagógico implantado foi baseado no mesmo princípio, ou seja, o da redução de investimentos governamentais. Ambos os programas foram avaliados logo após sua instalação, avaliações que já anunciavam as implicações desse modelo a baixo investimento governamental: 12 inadequação na formação de pessoal; insuficiência de materiais pedagógicos; precariedade das instalações e, até mesmo, da alimentação oferecida (Serpa, 1982; Melo, 1984). Apesar disso, o programa se expandiu.

As tendências atuais da educação infantil brasileira cristalizaram os modelos político e pedagógico de expansão adotados pelo governo federal no início da década de oitenta, o que transparece nas séries históricas organizadas a partir de dados consolidados pelo SEEC/MEC, apresentadas e discutidas adiante (Tabelas 2 e 3). Isto é, o modelo a baixo custo, apoiado numa concepção das "habilidades naturais" da mulher para o exercício da função de educadora infantil, impregnou o imaginário e as práticas sociais, generalizando-se como o modelo possível e adequado de educação infantil para o Brasil. Baseando-se no enfoque de compensação de carências de populações empobrecidas, o governo federal estimulou a abertura de

11. Por exemplo, encontramos a seguinte apresentação em documento da época: "O grupo de trabalho do Projeto Especial do Pré-Escolar, sob o título Proposta para um Atendimento Educacional a Crianças de 4 a 6 anos Provenientes de População de Baixa Renda, relacionou os princípios educacionais que nortearam, de acordo com a linha do Fundo das Nações Unidas para a Infância (UNICEF), sua atuação..." (Schlesinger, 198I. s.p).

12. Prefiro a expressão baixo investimento governamental à "baixo/custo", pois ela indica que o custo total do programa é indireta e parcialmente assumido pela comunidade através da cessão de espaços físicos, da subremuneração paga a seus serviços, além das implicações, a longo prazo, de um atendimento inadequado no plano da qualidade. 
vagas pela administração municipal, principalmente nas regiões Norte e Nordeste, que recrutou mão-de-obra não formada para atuar junto a crianças com idade próxima ou superior à prevista para o ingresso no ensino fundamental. Nota-se, pois, um deslizamento importante de sentido: a educação infantil destinada a crianças em idade anterior à educação compulsória, passou a ser entendida como educação anterior à educação compulsória, independentemente da idade da criança, fato atestado pelo número significativo de crianças tendo de sete a onze anos nos estabelecimentos de creche/pré-escola ( I ,2 milhão de acordo com a PNAD 95; Tabela 4) 13.

Sem dúvida, a expansão das matrículas no pré-escolar no período, pode receber o qualificativo de espetacular, quando se destacam os índices de crescimento (Tabelas 2 e 3): 1062, I \% no período 70-96 e 225,7\% entre 1980 e 1996. De forma regular e sistemática, ano a ano, a administração municipal passou a assumir, cada vez mais, a educação préescolar: responsável por apenas 12,9\% das matrículas iniciais em 1969, a administração municipal dobrou sua taxa de participação já em meados da década de setenta (era responsável por 26,4\% das matrículas iniciais em 1976), para assumir mais da metade do atendimento pré-escolar em 1996, quando 57,4\% das matrículas iniciais estavam sob sua responsabilidade.

Os índices de crescimento foram notáveis para os diferentes segmentos populacionais, independentemente do nível de renda, da localização rural ou urbana, pertencimento racial ou do sexo da criança (Tabela 5). Poder-se-ia pensar em democratização da oferta. Porém, a democratização da educação infantil no Brasil não pode ser analisada somente sob a ótica de sua expansão mas também das diferenciações internas decorrentes dessa expansão, e da articulação desse nível educacional com o ensino fundamental, como aconselhou Petitat ( 1994) para entender a democratização do ensino secundário francês.

Quando a atenção se volta para a composição etária das matrículas iniciais, constatase que a educação infantil brasileira tem se aproximado mais do modelo de antecipação da escolaridade pelo pré-escolar: a série histórica (Tabelas 2 e 3) mostra que a proporção de matrículas iniciais entre crianças com menos de quatro anos é pequena, tendo ocorrido uma inflexão na curva apenas em 1976. Porém, a mudança mais significativa no perfil da educação pré-escolar no período parece ter ocorrido em 1984, quando o Censo Educacional passou a incluir, também, os dados do Programa Nacional de Educação Pré-escolar implantado em 198 I pelo MOBRAL. Entre 1983 e 1984 observa-se um salto de aproximadamente 400 mil matrículas iniciais, correspondendo à inclusão da educação pré-escolar não formal no sistema de dados (Brasil, 1985b).

13. Em 1996, a PNAD calculava que 1.151.917 crianças tendo entre sete e onze anos freqüentavam pré-escolar ou classes de alfabetização. O Censo Escolar do mesmo ano (Brasil, 1997) informava que 1.417.980 matrículas em pré-escolar e classes de alfabetização eram ocupadas por crianças tendo sete anos e mais. Esta defasagem de 266.063 unidades entre ambas fontes pode ser explicada por diferentes razões, possivelmente associadas, a saber: uma criança pode ter se matriculado mais de uma vez; ausência de limite etário superior nos dados do MEC/INEP e limite etário de onze anos nos dados coletados pelo IBGE; época de coleta de dados divergindo em ambas as fontes; modo de calcular a idade da criança divergindo em ambas as fontes; desconhecimento, por parte da família (informante) do ano ou nível de ensino que a criança freqüenta (Rosemberg, 1999). 


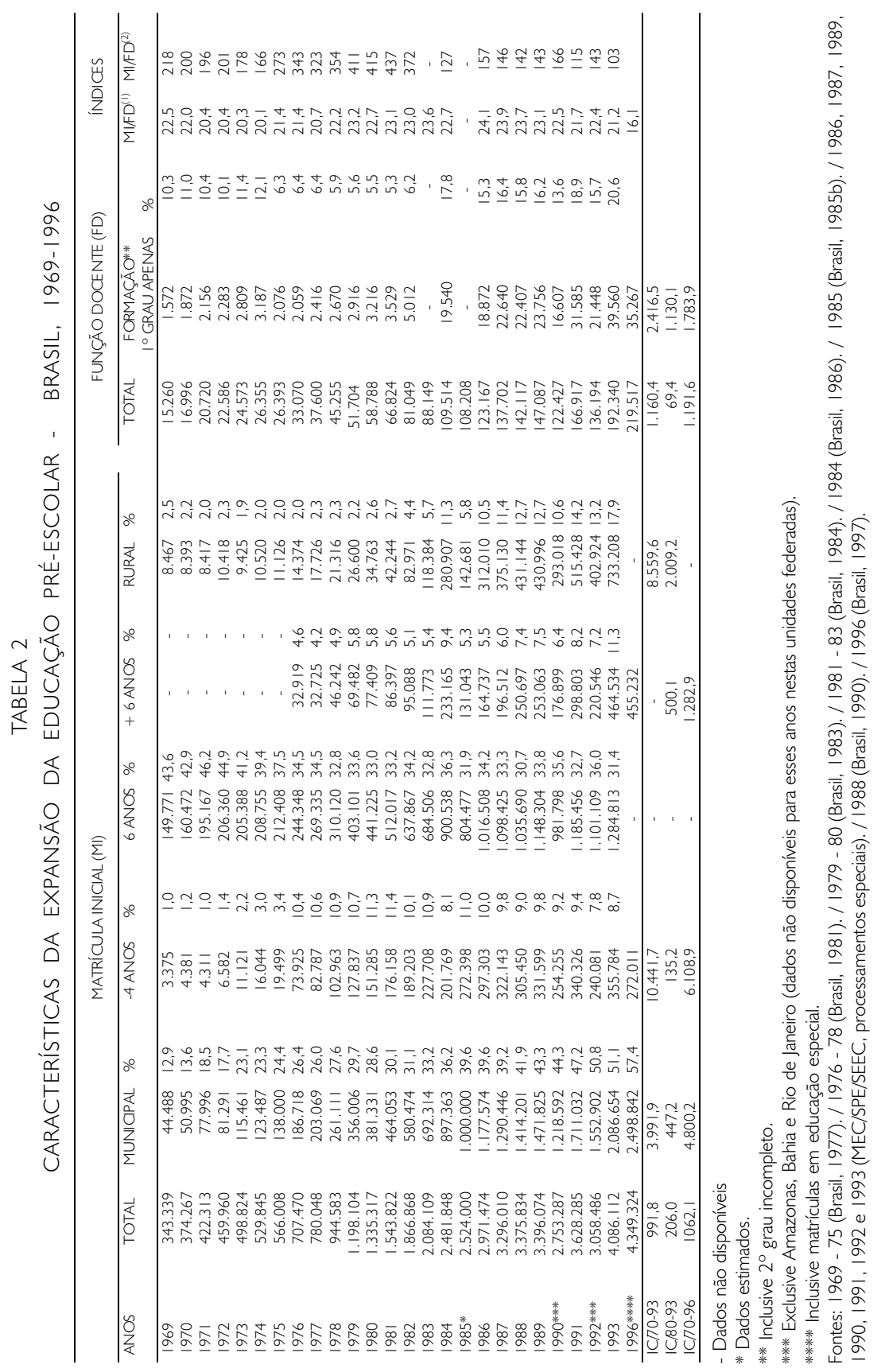




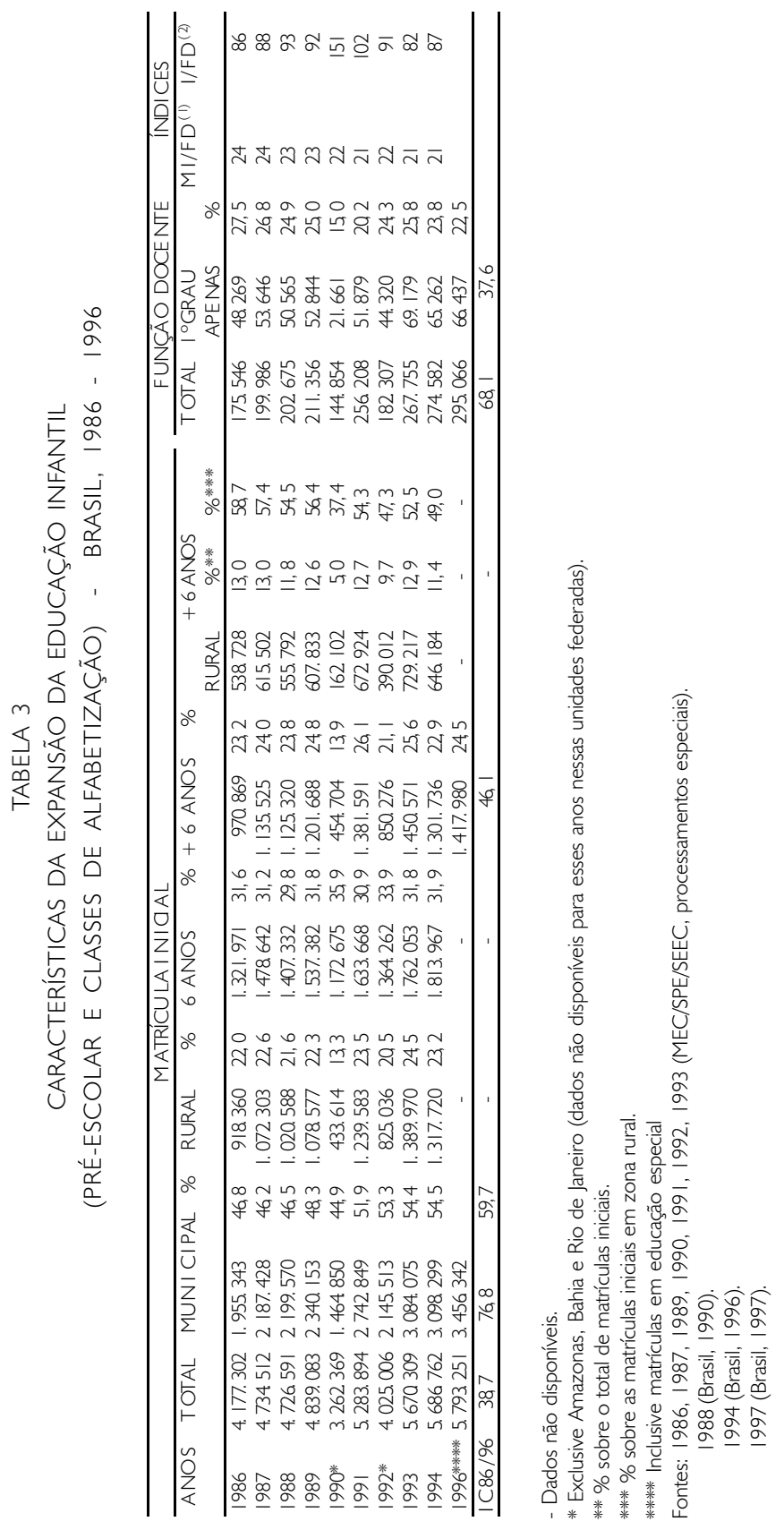


TABELA 4

TAXAS DE ESCOLARIDADE SEGUNDO VARIÁVEIS ESCOLHIDAS

E DATA DE COLETA DO DADO*

\begin{tabular}{|c|c|c|c|c|}
\hline VARIÁVEIS & ANO & $\begin{array}{c}\text { TAXA DE } \\
\text { ESCOLARIDADE }\end{array}$ & ANO & $\begin{array}{c}\text { TAXA DE } \\
\text { ESCOLARIDADE }\end{array}$ \\
\hline Crianças de 5 e 6 anos (geral) & $|98|$ & 23,6 & 1995 & 63,8 \\
\hline \multicolumn{5}{|l|}{ Crianças de 5 e 6 anos por raça } \\
\hline $\begin{array}{c}\text { brancas } \\
\text { negras }\end{array}$ & $\begin{array}{l}1982 \\
1982\end{array}$ & $\begin{array}{l}36,0 \\
327\end{array}$ & 1990 & $\begin{array}{l}52,7 \\
484\end{array}$ \\
\hline $\begin{array}{l}\text { Crianças de } 0 \text { a } 6 \text { anos por rendimento } \\
\text { familiar (sm) }\end{array}$ & 1982 & & 1989 & \\
\hline até $1 / 4$ & 1982 & 2,5 & 1989 & 14,8 \\
\hline de $1 / 4$ a $1 / 2$ & 1982 & 3,4 & 1989 & 17,9 \\
\hline de $1 / 2 \mathrm{al}$ & 1982 & 3,3 & 1989 & 25,3 \\
\hline+ de 1 a 2 & 1982 & 3,4 & 1989 & 40,6 \\
\hline+ de 2 & 1982 & 14,3 & 1989 & 60,6 \\
\hline
\end{tabular}

*Fontes: PNADS 81, 82, 89, 90, 95 apud Rosemberg (1997a)

TABELA 5

PERFIL DE CRIANÇAS DE 5 A I I ANOS QUE FREQÜENTAM A PRÉ-ESCOLA POR GRUPOS DE IDADE - BRASIL*, 1987, 1995

\begin{tabular}{|c|c|c|}
\hline \multirow{2}{*}{$\begin{array}{l}\text { ATRIBUTOS/ } \\
\text { DATA/IDADE }\end{array}$} & \multicolumn{2}{|c|}{ CRIANÇAS FRE QÜENTANDO PRÉ-ESCOLAR } \\
\hline & 5 e 6 ANOS & 7 a 9 ou 11 ANOS \\
\hline \multicolumn{3}{|l|}{ RAÇA (1995) - 7 a 9} \\
\hline Brancos & 53,0 & 32,3 \\
\hline Negros (Pretos + Pardos) & 47,0 & 67,7 \\
\hline Total & 3.389 .158 & 1.064 .396 \\
\hline \multicolumn{3}{|l|}{$\operatorname{SEXO}(1995)-7$ a 1 I } \\
\hline Homens & 49,9 & 53,5 \\
\hline Mulheres & 50,1 & 46,5 \\
\hline Total & 3.489 .222 & 1.216 .454 \\
\hline \multicolumn{3}{|l|}{ RENDA FAMILIAR PER CAPITA } \\
\hline \multicolumn{3}{|l|}{$(1987)-7$ a 9} \\
\hline até $1 / 4$ & 13,0 & 35,6 \\
\hline $1 / 4$ a $1 / 2$ & 17,2 & 25,0 \\
\hline $1 / 2$ a 1 & 23,3 & 18,4 \\
\hline I a 2 & 21,2 & 10,5 \\
\hline 2 a 3 & 8,7 & 4,1 \\
\hline+3 & 14,4 & 4,7 \\
\hline Total & 2.904 .951 & 1.024 .558 \\
\hline \multicolumn{3}{|l|}{ LOCALIZAÇÃO (1987) - 7 a 9} \\
\hline Urbana & 84,7 & 60,0 \\
\hline Rural & 15,3 & 40,0 \\
\hline Total & 2.904 .951 & 1.024 .558 \\
\hline \multicolumn{3}{|c|}{ REGIÃO DE RESIDÊNCIA (1995) - 7 a I I } \\
\hline Norte* & 5,6 & 5,3 \\
\hline Nordeste & 36,5 & 66,2 \\
\hline Sudeste & 42,5 & 21,8 \\
\hline Sul & 9,6 & 2,5 \\
\hline Centro-Oeste & 5,8 & 4,1 \\
\hline Total & 3.489 .222 & 1.216 .454 \\
\hline
\end{tabular}

Exclusive zona rural da região Norte.

* Fontes: tabulações especiais das PNADs 87, 90; CD-RON de microdados PNAD 95. 
Na passagem de 1983 para 1984 observam-se, então, algumas inflexões importantes na série histórica associadas a esse aumento do número de matrículas iniciais: aumento significativo da matrícula inicial em zona rural (137,3\% de crescimento entre 83/84), de crianças tendo mais de seis anos ( 198, 1 \% de crescimento nas matrículas iniciais entre 83/84) e residentes na região Nordeste (68,8\% das novas matrículas iniciais ocorreram nessa região). Das 397.739 novas matrículas iniciais compulsadas pelo Censo Educacional de 1984 , 81 ,8\% distribuíram-se em apenas sete estados: Maranhão (22,7\%), Bahia ( 17,2\%), Minas Gerais (12,8\%), Ceará ( I I,0\%), Paraná (7,2\%), Goiás (5,9\%) e Pernambuco (5,0\%). Alguns desses estados, em especial os do Nordeste, ampliaram a matrícula principalmente para crianças tendo seis anos e mais graças ao trabalho de professores(as) leigos(as).

Juntamente com a entrada de 397.739 novas matrículas iniciais em 1984, foram registradas no sistema pré-escolar mais 14.528 funções docentes com formação inferior ao $2^{\circ}$ grau completo (o que se tem denominado professores leigos). Assim, se aceitarmos a razão número de crianças por adulto de $1983(23,6)$, essas novas funções docentes leigas seriam, praticamente, responsáveis por quase todo o processo de expansão: as 14.528 novas professoras leigas teriam assumido 342.860 novas matrículas, ou seja, 86,2\% da expansão. Não só as professoras leigas deram conta da expansão naquele momento, como observa-se, na série histórica, a instalação desse modelo evidenciado pelo aumento, quase que contínuo no magistério pré-escolar, da participação de educadoras tendo cursado apenas o $1{ }^{\circ}$ grau. Em 1996, 22,5\% das professoras de educação infantil (pré-escolar e classes de alfabetização) encontravam-se nessa situação (Tabelas 2 e 3). Além disso, nota-se uma tendência ao aumento da proporção de crianças tendo sete anos e mais nas pré-escolas e classes de alfabetização (Tabelas 2 e 3).

A "laicização" do corpo docente na educação infantil foi acompanhada do fenômeno inverso no ensino fundamental: se em 1985, 14,4\% do magistério no ensino fundamental era leigo, em 1987 esta cifra caiu para I I\%, para atingir a porcentagem de 9\% em 1996 (de I a à $8^{\mathrm{a}}$ série). A desvalorização da educação infantil parece acompanhada de uma tendência à valorização do ensino fundamental. No plano dos(as) alunos(as), a educação infantil acolhe e retém segmentos da população com os maiores índices de exclusão no ensino fundamental: crianças pobres e negras.

A opção por expandir a educação infantil com um modelo não formal apoiado nos baixos salários de professoras leigas, prioritariamente para as regiões Norte e Nordeste, diferenciou o padrão de oferta do atendimento não só quanto ao desenvolvimento regional mas, também, quanto aos segmentos raciais. Com efeito, a composição racial da população brasileira - infantil, juvenil e adulta - apresenta intensa variação regional. Os não-brancos (conjunto de pessoas classificadas como pretas e pardas), que perfaziam 45\% da população em 1995, representavam 71,3\% dos residentes na região Norte e Nordeste e apenas 15,2\% na região Sul (Fonte: PNAD 95).

Essa diversidade na composição racial dos residentes nas diferentes regiões fisiográficas tem sido explicada, em parte, por fatores históricos: a configuração do sistema do trabalho 
escravo no final do século XIX e a política imigrantista. Segundo Hasenbalg ( 1988), em I 872, $35 \%$ e, em 1890, $41 \%$ dos brancos estavam na região Sudeste ${ }^{14}$, enquanto apenas $21 \%$ e 20\% dos pretos e pardos aí habitavam nestas mesmas datas. Essa tendência acentuou-se nos anos posteriores. Em 1940, 52\%, em 1950, 56\% da população branca residia na região Sudeste. Em 1995, de acordo com dados da PNAD, considerando-se a mesma divisão adotada por Hasenbalg (Sudeste mais Sul), esse percentual subia para 62,0\%, enquanto apenas $37,4 \%$ dos não-brancos habitavam aquela região.

Na faixa etária de 0 a 6 anos de idade, encontramos composição racial equivalente ao conjunto da população, bem como padrão equivalente de distribuição pelo território nacional: em 1987, neste grupo etário, 54,4\% das crianças foram declaradas brancas e 45, 1 \% pretas e pardas (PNAD, apud Rosemberg, Pinto, 1997). Porém, esta média nacional esconde intensas diferenças regionais. As crianças pretas e pardas superam as brancas, justamente nas regiões economicamente menos desenvolvidas: na zona rural para o conjunto do território nacional; nas regiões Norte, Nordeste e Centro-Oeste. Associando-se densidade populacional e composição racial, observa-se que as crianças brancas residem principalmente no Sudeste (70,4\%) e as não-brancas principalmente no Nordeste (49,8\%). Desse modo, foram principalmente as crianças pretas e pardas que se defrontaram com o modelo de educação infantil não-formal introduzido no início da década de oitenta o que acarretou impacto no perfil racial do usuário dos diferentes programas oferecidos.

A opção por expandir a educação infantil nas regiões Norte e Nordeste, através de um modelo a baixo investimento, a cargo de professoras leigas, configurou um significado bastante peculiar aos indicadores de cobertura. Os índices de cobertura em educação infantil não têm o mesmo significado em todos os estados e tampouco o mesmo significado que os índices de cobertura no ensino fundamental. Isto é, não significam democratização da educação, mas sim um processo de "democratização", como se descutirá no próximo tópico.

\section{DEMOCRATIZAÇÃO OU "DEMOGRAFIZAÇÃO"?}

Para aprofundar esta análise em base empírica, recorri a um tratamento estatístico de dados envolvendo oito variáveis desagregadas por Unidades da Federação (Quadros | e 2): relativas a indicadores de desenvolvimento (índice de desenvolvimento humano - IDH -, calculado pelo IPEA/PNUD); composição racial (porcentagem de negros - pretos e pardos na população residente nas unidades da federação); taxa de escolaridade de crianças de zero a seis anos no pré-escolar e indicadores educacionais (porcentagem de crianças tendo entre sete e onze anos no pré-escolar; porcentagem de funções docentes no pré-escolar com formação inferior ao $2^{\circ}$ grau; taxa de escolaridade entre crianças de sete a onze anos no ensino fundamental e rendimento escolar na prova de português na $I^{a}$ série do $1^{\circ} \mathrm{grau}$ ).

14. É importante lembrar que a região Sudeste, de que fala Hasenbalg ( 1983), englobava, praticamente, as atuais regiões Sudeste e Sul, segundo a divisão dos censos demográficos e das PNADs. Ela abrangia os atuais estados do Rio de Janeiro, São Paulo, Paraná, Santa Catarina e Rio Grande do Sul, e não incluía o Estado de Minas Gerais. 


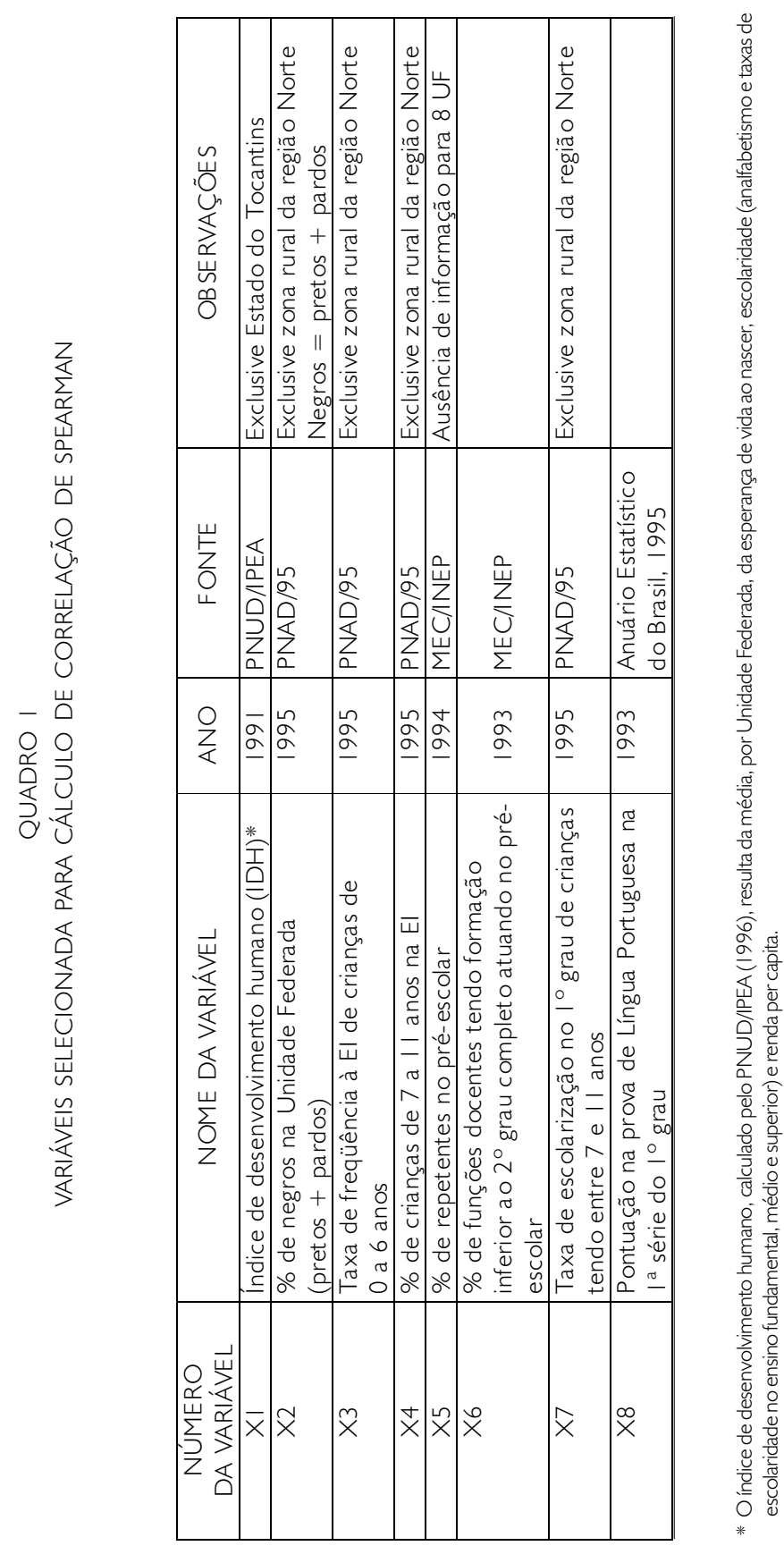


QUADRO 2

ÍNDICES DE VARIÁVEIS SOCIORRACIAIS E DE ESCOLARIDADE POR UNIDADES DA FEDERAÇÃO

\begin{tabular}{|c|c|c|c|c|c|c|c|c|}
\hline $\begin{array}{l}\text { UNDADESDA } \\
\text { FEDRAÇAOA } \\
\text { (UF) }\end{array}$ & $\begin{array}{l}X / * \\
\\
\text { IDH } \\
\text { I99/ }\end{array}$ & $\begin{array}{l}\text { X2** } \\
\text { \%DE } \\
\text { NEGROS } \\
199\end{array}$ & $\begin{array}{c}\text { X3*** } \\
\text { TAXADE } \\
\text { FREQÜENCIA } \\
\text { AOPRÉ- } \\
\text { ECOLAR } \\
0-6 \\
199\end{array}$ & $\begin{array}{c}\text { X4*** } \\
\% \text { \%E } \\
\text { CRIANÇAS DE7 } \\
\text { a // NOPRÉ- } \\
\text { ECOLAR 1995 }\end{array}$ & $\begin{array}{c}\text { REPETENTES } \\
1994\end{array}$ & $\begin{array}{c}\text { X6***** } \\
\text { \% FUNÇÕES } \\
\text { DOCENTES } \\
\text { TENDO } \\
\text { FORMAÇÃO } \\
\text { INFERIORA2 } A 2^{\circ} \\
\text { GRAU NO PRÉ } \\
\text { I993 }\end{array}$ & $\begin{array}{c}X 7^{* * *} \\
\text { TAXADE } \\
\text { ECCOLA } \\
\text { RDDADE } 7 a \\
\text { // ANOS NO } \\
\text { P GRAU } \\
199\end{array}$ & $\begin{array}{c}\text { X8****** } \\
\text { RENDI- } \\
\text { MENTO } \\
\text { ECOLAR QM } \\
\text { PORTUGUÊS } \\
\text { a SÉRIE } \\
1993\end{array}$ \\
\hline
\end{tabular}

\begin{tabular}{|c|c|c|c|c|c|c|c|}
\hline Ro & 0,715 & 57,9 & 25,7 & 14,6 & 0,0 & 18,5 & 92,0 \\
\hline
\end{tabular}

\begin{tabular}{|l|l|l|l|l|l|l|l|l|}
\hline Acre & 0,665 & 71,2 & 28,5 & 5,7 & 0,3 & 16,9 & 89,3 & 63,4 \\
\hline
\end{tabular}

\begin{tabular}{|c|c|c|c|c|c|c|c|}
\hline Amazonas & 0,797 & 71,8 & 22,7 & 19,1 & 20,2 & 44,0 & 63,7 \\
\hline Roraima & 0,749 & 66,5 & 25,8 & 0,0 & 27,5 & 96,3 & 44,1 \\
\hline
\end{tabular}

\begin{tabular}{|c|c|c|c|c|c|c|c|c|}
\hline \begin{tabular}{|l|} 
Pará \\
\end{tabular} & 0,688 & 74,2 & 28,1 & 28,0 & 16,2 & 51,0 & 82,1 & 60,5 \\
\hline Amapá & 0,781 & 64,7 & 18,5 & 16,7 & 0,0 & 11,9 & 88,2 & 49.5 \\
\hline
\end{tabular}

\begin{tabular}{|c|c|c|c|c|c|c|c|c|}
\hline Tocantins & - & 75,4 & 16,9 & 326 & 17,1 & 50,9 & 826 & 466 \\
\hline Maranhão & 0,512 & 79,2 & 30,5 & 46,2 & & 40,1 & 67,1 & 53,3 \\
\hline
\end{tabular}

\begin{tabular}{|c|c|c|c|c|c|c|c|c|}
\hline Maranhão & 0,512 & 79,2 & 30,5 & 46,2 & & 40,1 & 67,1 & 53,3 \\
\hline Piauí & 0,502 & 80,9 & 27,8 & 35,7 & 14,7 & 44,3 & 76,1 & 48,8 \\
\hline Ceará & 0,506 & 68,6 & 27,9 & 48,0 & 0,0 & 41,4 & 65,2 & 58,3 \\
\hline $\begin{array}{l}\text { Rio Grande do } \\
\text { Norte }\end{array}$ & 0,574 & 63,5 & 29,7 & 8,7 & 2,9 & 23,3 & 87,7 & 58,7 \\
\hline Paraíba & 0,466 & 65,9 & 27,9 & 38,4 & 34,2 & 48,3 & 73,4 & 68,4 \\
\hline Pernambuco & 0,577 & 62,2 & 26,2 & 25,6 & 8,1 & 11,2 & 79,4 & 53,7 \\
\hline Alagcas & 0,500 & 63,8 & 21,2 & 25,7 & 3,8 & 43,0 & 66,0 & 38,3 \\
\hline Sergipe & 0,663 & 82,5 & 28,3 & 25,7 & 1,5 & 33,7 & 82,9 & 67,7 \\
\hline Bahia & 0,609 & 78,2 & 23,5 & 46,5 & & 41,5 & 70,1 & 60,1 \\
\hline Minas Gerais & 0,779 & 45,5 & 22,1 & 20,7 & 0,0 & 4,7 & 89,5 & 63,7 \\
\hline Espírito Santo & 0,816 & 52,7 & 23,9 & 2,3 & 0,1 & 3,2 & 90,9 & 54,1 \\
\hline Rio de Janeiro & 0,838 & 38,7 & 31,7 & 22,7 & & 6,5 & 87,6 & 65,9 \\
\hline São Paulo & 0,858 & 23,7 & 28,2 & 7,9 & & 1,8 & 94,5 & 71,2 \\
\hline Paraná & 0,827 & 23,7 & 20,5 & 4,0 & & 10,9 & 93,5 & 65,1 \\
\hline Santa Catarina & 0,842 & 7,3 & 23,6 & 6,2 & 0,0 & 19,1 & 94,4 & 70,8 \\
\hline Rio Grande do Sul & $0,87 \mid$ & 11,4 & 26,2 & 8,8 & 0,0 & 2,6 & 94,3 & 69,1 \\
\hline Mato Grosso do Sul & 0,826 & 37,7 & 18,7 & 6,8 & 0,0 & 6,3 & 90,6 & 71,5 \\
\hline Mato Grosso & 0,769 & 61,0 & 16,5 & 15,8 & 0,0 & 12,7 & 90,9 & 71,5 \\
\hline Goiás & 0,760 & 56,1 & 20,1 & 32,6 & & 18,6 & 84,1 & 55,1 \\
\hline Distrito Federal & 0,858 & 41,5 & 30,1 & 15,0 & 0,0 & 0,9 & 92,7 & 73,2 \\
\hline
\end{tabular}

Fontes: * PNUD/IPEA(1996).

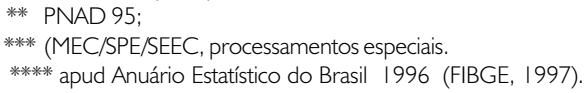

No Quadro 3, foram transcritos os r de Spearman e os níveis de significância entre as variáveis sociorraciais $(X \mid$ e $X \mid$ ) e seis dos indicadores educacionais. Sua análise permite observar, em primeiro lugar, que as taxas de escolaridade no pré-escolar e no ensino fundamental comportam-se de modo diferente: enquanto a taxa de escolaridade no ensino fundamental entre crianças de sete a onze anos $(X 7)$ apresenta alta correlação positiva com o índice IDH $(X \mid)$ e alta correlação negativa com a porcentagem de negros na população $(X 2)$, 
a taxa de freqüência ao pré-escolar não apresenta nenhum coeficiente com nível de significância que permita aceitar correlação entre as variáveis. Assim, enquanto a escolaridade de sete a onze anos no ensino fundamental é mais intensa nas unidades da federação mais ricas, mais instruídas e mais brancas, o mesmo não se observa com a taxa de freqüência ao pré-escolar.

$$
\text { QUADRO } 3
$$

COEFICIENTES DE CORRELAÇÃO DE SPEARMAN ENTRE VARIÁVEIS SOCIORRACIAIS E EDUCACIONAIS DE ACORDO COM O RANKING OCUPADO PELAS UNIDADES DA FEDERAÇÃO

\begin{tabular}{|c|c|c|c|c|}
\hline VARIÁVEIS & & $\begin{array}{l}\mathrm{XI} \\
\mathrm{IDH}\end{array}$ & & $\begin{array}{c}\times 2 \\
\% \text { de negros na } \\
\text { população }\end{array}$ \\
\hline $\begin{array}{l}\text { X3 } \\
\text { taxa de freqüência a o pré- } \\
\text { escolar }(0 \text { a 6) }\end{array}$ & $\begin{array}{l}r \\
\mathrm{p} \\
\mathrm{n}\end{array}$ & $\begin{array}{r}-0,157 \\
0,444 \\
26\end{array}$ & $\begin{array}{l}r \\
\mathrm{p} \\
\mathrm{n}\end{array}$ & $\begin{array}{r}0,151 \\
0,460 \\
27 \\
\end{array}$ \\
\hline $\begin{array}{l}\text { X4 } \\
\% \text { de crianças de } 7 \text { a II } \\
\text { anos no pré }\end{array}$ & $\begin{array}{l}\mathrm{r} \\
\mathrm{p} \\
\mathrm{n}\end{array}$ & $\begin{array}{c}-0,622 * * \\
0,001 \\
26 \\
\end{array}$ & $\begin{array}{l}\mathrm{r} \\
\mathrm{p} \\
\mathrm{n}\end{array}$ & $\begin{array}{l}0,604 * * \\
0,001 \\
27\end{array}$ \\
\hline $\begin{array}{l}\text { X5 } \\
\text { repetência no pré-escolar }\end{array}$ & $\begin{array}{l}r \\
\mathrm{p} \\
\mathrm{n}\end{array}$ & $\begin{array}{c}-0,729 * * \\
0,001 \\
18 \\
\end{array}$ & $\begin{array}{l}\mathrm{r} \\
\mathrm{p} \\
\mathrm{n}\end{array}$ & $\begin{array}{c}0,677^{*} * \\
0,001 \\
19\end{array}$ \\
\hline $\begin{array}{l}\text { X6 } \\
\% \text { de funções docentes com } \\
\text { formação inferior } \\
\text { a } 2^{\circ} \text { grau }\end{array}$ & $\begin{array}{l}r \\
\mathrm{p} \\
\mathrm{n}\end{array}$ & $\begin{array}{c}-0,814 * * \\
0,000 \\
26 \\
\end{array}$ & $\begin{array}{l}\mathrm{r} \\
\mathrm{p} \\
\mathrm{n}\end{array}$ & $\begin{array}{l}0,779 * * \\
0,000 \\
27\end{array}$ \\
\hline $\begin{array}{l}\text { X7 } \\
\text { taxa de escolaridade } 7 \\
\text { a II no ensino fundamental }\end{array}$ & $\begin{array}{l}r \\
\mathrm{p} \\
\mathrm{n}\end{array}$ & $\begin{array}{c}0,718^{*} * * \\
0,000 \\
26\end{array}$ & $\begin{array}{l}\mathrm{r} \\
\mathrm{P} \\
\mathrm{n}\end{array}$ & $\begin{array}{c}-0,702^{*} * * \\
0,000 \\
27 \\
\end{array}$ \\
\hline 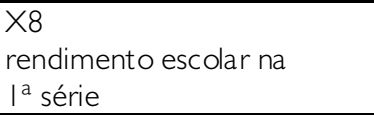 & $\begin{array}{l}\mathrm{r} \\
\mathrm{p} \\
\mathrm{n}\end{array}$ & $\begin{array}{c}0,584 * * \\
0,002 \\
26\end{array}$ & $\begin{array}{l}\mathrm{r} \\
\mathrm{p} \\
\mathrm{n}\end{array}$ & $\begin{array}{c}-0,520 * * \\
0,005 \\
27\end{array}$ \\
\hline
\end{tabular}

* Correlação é significante no nível de 5\% para teste estatístico bicaudal ( $\mathrm{HO}$ : ro $=0$ ).

** Correlação é significante no nível de I\% para teste estatístico bicaudal ( $\mathrm{HO}$ : ro = 0).

Em segundo lugar, observa-se um comportamento oposto entre a escolaridade de crianças tendo de sete a onze anos no ensino fundamental e no pré-escolar: enquanto o primeiro indicador de escolaridade apresenta alta correlação positiva com o IDH $(X \mid)$ e presença de brancos na unidade federada $(X 2)$, a presença de crianças desse grupo etário no pré-escolar (X4) está inversamente associada aos índices de desenvolvimento humano $(X \mid)$ e diretamente associada à presença de negros $(X 2)$.

Também a correlação entre rendimento escolar na $1^{a}$ série do $1^{\circ}$ grau (X8) está diretamente associada ao índice de desenvolvimento humano (IDH) e inversamente associada 
à presença de negros na unidade federada. Portanto, os piores resultados na prova de português na la série estão associados ao menor desenvolvimento da unidade federada, bem como à maior presença de negros aí residentes.

Os maiores índices de repetência no pré-escolar estão inversamente associados ao nível de renda do chefe e diretamente associados à sua baixa escolaridade e à porcentagem de negros na unidade federada. Assim, nas unidades federadas mais pobres, com pior nível de escolaridade e com presença mais acentuada de negros encontram-se, também, os maiores índices de reprovação no pré-escolar.

Finalmente, a freqüência de funções docentes com formação inferior ao $2^{\circ}$ grau $(X 7)$ está inversamente relacionada com o índice de desenvolvimento e diretamente relacionada à presença de negros $(X 2)$.

Em conclusão: quanto menos desenvolvida e mais negra a unidade da federação, maior a porcentagem de crianças tendo sete anos e mais que freqüentam a pré-escola e maior a porcentagem de funções docentes com formação inferior ao $2^{\circ}$ grau. São estas unidades da federação que ocupam, também, postos inferiores quanto aos indicadores de escolaridade no $1^{\circ}$ grau: são piores as taxas de escolaridade no ensino fundamental entre sete e onze anos e piores os resultados das crianças freqüentando a $l^{\mathrm{a}}$ série do $I^{\circ}$ grau na prova de português.

No Quadro 4, foram transcritos os coeficientes de correlação entre os indicadores de escolaridade. Observa-se que o maior índice de crianças entre zero e seis anos no préescolar (X3) não apresenta associação com nenhuma das variáveis selecionadas (X6, X7 e X8). Porém, a maior freqüência de crianças entre sete e onze anos no pré configura um outro padrão: está diretamente associada à presença de professores(as) leigos(as) (X6) e inversamente associada ao índice de escolaridade de sete a onze anos no ensino fundamental (X7). Isto é, unidades federadas onde se encontram maiores porcentagens de crianças tendo sete e onze anos no pré-escolar, são também aquelas em que se encontram maiores porcentagens de professores leigos e menores índices de escolaridade no ensino fundamental. Isso pode significar que o pré-escolar está sendo usado como alternativa à educação fundamental para segmentos diferenciados de crianças.

Os índices de repetência no pré-escolar $(X 5)$ estão diretamente associados à presença de professores(as) leigos(as) (X6), inversamente associados aos índices de escolaridade no $1^{\circ}$ grau (X7) e a bons níveis de rendimento na prova de português realizada na $I^{a}$ série do $1^{\circ}$ grau (X8). Isto é, a repetência no pré-escolar se associa à baixa qualificação do(a) professor(a) e à baixa rentabilidade do sistema.

Finalmente, os melhores resultados na prova de português na Ia série (X8) foram registrados naquelas unidades da federação em que no pré-escolar encontram-se menores porcentagens de professores leigos e melhores índices de escolaridade no ensino fundamental para crianças entre sete e onze anos. 
QUADRO 4

COEFICIENTES DE CORRELAÇÃO DE SPEARMAN

ENTRE INDICADORES EDUCACIONAIS DE ACORDO COM

O RANKING OCUPADO PELAS UNIDADES DA FEDERAÇÃO

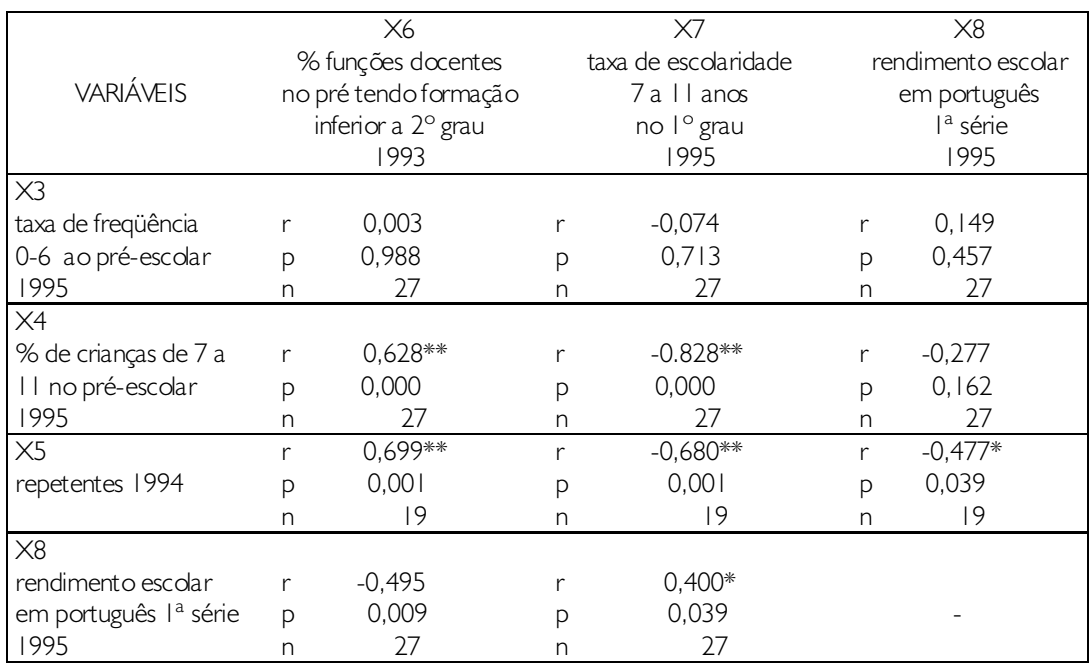

* Correlação é significante no nível de 5\% para teste estatístico bicaudal ( $\mathrm{HO}$ : ro $=0$ ).

* Correlação é significante no nível de $1 \%$ para teste estatístico bicaudal ( $\mathrm{HO}$ : ro = 0).

Em resumo, a expansão da educação infantil, ou as melhores taxas de cobertura de educação infantil, em si não constituem bons indicadores de desenvolvimento, sejam socioeconômicos ou educacionais. Para que isso ocorra é necessário qualificar o índice de cobertura: se atende à população de crianças na faixa etária prevista com professoras qualificadas para a função. Nesse sentido, a expansão da educação infantil não significa obrigatoriamente um processo de democratização da educação mas pode significar uma realocação, no sistema educacional, de segmentos sociais excluídos. Como dizem os franceses, em vez de democratização estaria ocorrendo um processo de "demografização". No caso brasileiro, a inclusão acarreta, paradoxalmente, a exclusão.

\section{CONCLUSÕES}

A desqualificação da educação infantil constitui fenômeno quase que universal em decorrência de sua vinculação à esfera da produção da vida (Cochran, 1993). Em vários países desenvolvidos, principalmente da Europa, tem-se observado, porém, um movimento para sua qualificação.

Em primeiro lugar, a própria dinâmica da vida social levou à expansão da oferta com padrões de qualidade compatíveis, em muitos países, com as exigências de uma crescente 
população usuária de classe média. Assim, a participação maciça de mulheres de diferentes estratos sociais no mercado de trabalho e a inexistência (ou custo) de empregadas domésticas como retaguarda, pressionaram a demanda dentro de padrões de qualidade satisfatórios.

Em segundo lugar, políticas afirmativas para a igualdade de oportunidades entre os sexos têm levado, também, à requalificação da educação infantil, principalmente no contexto da União Européia. Por exemplo, a Comissão Européia, órgão executivo da União Européia, conta com um Conselho Consultivo de Educação Infantil enquadrado no programa de igualdade de oportunidades para os sexos. Em 1992, o Conselho de Membros da Comunidade Européia adotou uma recomendação sobre o atendimento à criança pequena que foi aprovada pelos doze Estados-membros, tendo sido operacionalizada na proposição de critérios de qualidade dos serviços para crianças pequenas que envolvem, inclusive, o estímulo à atuação do homem como provedor de cuidados em equipamentos de educação infantil (Jensen, 1993) ${ }^{15}$.

No Brasil, o processo histórico não se tem dado no mesmo sentido. Apesar de o Movimento de Mulheres ter participado intensamente da mobilização por creches durante os anos setenta e oitenta (o que redundou no reconhecimento do direito da criança à educação antes dos sete anos pela Constituiçãa de 1988), as profundas desigualdades sociais mantêm, de um lado, ainda uma grande disponibilidade de empregadas domésticas (que oferecem retaguarda para as famílias de classe média, possivelmente minimizando conflitos familiares) e, de outro, uma profunda segregação social na utilização de equipamentos sociais ${ }^{16}$.

A expansão a baixo investimento e a persistência de modelos institucionais diversificados - creches públicas e creches conveniadas, pré-escolas públicas e conveniadas, classes de alfabetização -, geralmente abrem possibilidades ao oferecimento simultâneo de serviços com qualidade extremamente desigual. É essa desigualdade no custeio/qualidade que penaliza crianças pobres e negras de diferentes formas, desigualdade que tenho denominado "morte educacional anunciada".

Parece-nos urgente eliminar no Brasil as trajetórias paralelas de educação infantil. É inadmissível que creches e pré-escolas constituam alternativas ao ensino fundamental para crianças pobres e negras. Os dados sugerem também a falácia de que os problemas enfrentados pelo ensino fundamental (sua baixa eficácia) brotam apenas desse nível de ensino: a socialização de crianças pobres e negras para a subalternidade se inicia no berçário onde se encontram, de maneira geral, as trabalhadoras de creche com nível educacional inferior e crianças vivenciando rotinas de espera: espera do banho, da comida, da troca de fraldas, do brinquedo.

15. Apesar de ser questionável o impacto da presença, por si só, de homens na valorização da função (Saparolli, 1997).

16. A Pesquisa Nacional sobre Demografia e Saúde de 1996 (BEMFAM, 1997. p.37) encontrou, para a amostra de mulheres entrevistadas ( 15 a 49 anos) que, dentre aquelas que trabalham fora tendo filhos menores de cinco anos, II,6\% delegavam o cuidado da criança à empregada doméstica, 10,3\% à escola ou creche e 34,3\% a outros parentes (que não filhos/as). 
O caminho que nos parece mais adequado neste momento para superar o intrincado jogo de subordinações de classe, raça, gênero e idade, que vem prejudicando crianças através da educação infantil, seria o da formação e qualificação da trabalhadora que lida diretamente com a criança. Educação formal com qualificação profissional poderia angariar maior dignidade à função, desempenhada por mulheres, de cuidar e educar crianças pequenas. Vou me deter mais neste aspecto.

Como evidenciou pesquisa realizada pelo Centro de Cultura Luiz Freire (1994), na Região Metropolitana do Recife, sobre escolas populares (que incluem creches e pré-escolas), trabalhar nessas instituiç̧̃̃es, mesmo com baixos salários, pode significar iniciação profissional para algumas mulheres. Há algumas evidências de que a abertura de creches nem sempre responde à necessidade da demanda por vagas, mas à ampliação de mercado de trabalho para mulheres com baixo nível de instrução (Naspolini, comunicação pessoal, 1994)17. Como observou Beatty para os EUA, no Brasil também a expansão de vagas dos programas nacionais da LBA e do MEC abriram outras oportunidades de emprego para mulheres com pequeno nível de instrução nas regiões mais pobres do país.

Essa ampliação de mercado de trabalho por meio de programas não formais também beneficia mulheres e homens dos estratos sociais médios, que ocupam cargos técnicos na administração e supervisão desses programas, pois quanto menos qualificada a pessoa que lida diretamente com a criança, maior respaldo necessita de pessoal qualificado para dar suporte a seu trabalho ${ }^{18}$.

Essa concepção desqualificante de educação infantil atinge também a organização do sistema público de ensino, evidenciada pelas ações administrativas ou pela reação de professoras diante da burocracia escolar. Na dinâmica de resistências de professoras e diretoras diante dos desafios do ensino fundamental, são "encontradas", no pré-escolar, docentes "à espera": em período de gestação, às vésperas de aposentadoria (Silva, 1991). Walburga Arns Silva refere-se à situação da pré-escola, do ponto de vista dos docentes, como um "lugar de passagem". Para as professoras, trabalhar na pré-escola, pode significar não ter de enfrentar crianças mais críticas, mais ativas, mais competentes: "meu projeto é ir trabalhar com o ${ }^{\circ}$ grau, mas ainda não estou preparada. Precisa ter mais experiência e mais preparo"... (professora de maternal e prezinho, com $3^{\circ}$ grau - pedagogia, entrevistada por Ana Beatriz Cerizara, 1995. p.24). Como vimos, no período analisado, o contingente de professoras leigas simultaneamente diminuia no ensino fundamental enquanto aumentava no pré-escolar. Uma requalificação do corpo docente no ensino fundamental é acompanhada de uma desqualificação

17. Relatório de avaliação sobre o Programa Nacional de Educação Pré-escolar no Sergipe informa que, naquele estado, as diretoras recebiam uma complementação salarial proporcional à ampliação de vagas (lotação máxima) nas classes de pré-escolar (Silva, 1991).

18. Franco (1989) mostrou que no programa de creche domiciliar (o modelo menos formal disponível no Brasil), o conjunto de crecheiras que atendiam as crianças, bastante numeroso, custava menos que o quadro técnico que lhe servia de apoio, pouco numeroso. 
do professorado da educação infantil enquanto aumenta também neste nível escolar a proporção de crianças acima da idade, pelo processo de retenção de certos segmentos de alunos: especialmente pobres, negros e de sexo masculino. $\bigcirc$ ensino fundamental "depura-se" pela educação infantil que retém alunos(as) candidatos(as) ao fracasso, e professoras à espera ${ }^{19}$.

De um lado, o processo de expansão da educação infantil a baixo investimento aconteceu e cristalizou-se, principalmente, em unidades da federação com população majoritariamente não branca. Com certeza, esses programas abriram oportunidades de emprego para mulheres com pequena instrução e originárias dos estratos menos privilegiados da população, possivelmente, algumas delas, tendo filhos na faixa de idade de zero a seis anos, usuários reais ou potenciais de estabelecimentos de educação infantil. Indiretamente crianças pequenas poderiam estar se beneficiando dessa ampliação do mercado de trabalho para suas mães. Mas qual a relação custo/benefício?

A pergunta procede na medida em que a educação infantil, em seu processo de expansão, também criou e reforçou padrões de exclusão social e racial: crianças pobres e negras (em percentual ligeiramente mais freqüente entre meninos), mesmo no sistema de educação infantil público, freqüentam estabelecimentos de pior qualidade e que lhes impõem nível educacional inadequado à idade. Estabelecimentos de educação infantil de pior qualidade tanto significam lugares piores para educação e cuidado das crianças, quanto piores locais de trabalho para os adultos. Locais de produção e reprodução da subalternidade. Mulheres, resistindo ao destino de empregadas domésticas, acomodando-se às sobras do sistema. Crianças, desde muito cedo, sendo socializadas para a subalternidade.

No plano macro, apontamos como o padrão de segregação racial no país imprimiu um componente de discriminação racial à implantação de política de expansão da educação infantil. No plano micro, o mesmo padrão de segregação espacial, associado às trajetórias paralelas de educação infantil e de educação em geral para crianças maiores (sete a onze anos), e aos preconceitos social e racial, praticados cotidianamente no sistema educacional, permitem entender os "guetos" sociorraciais observados. Não encontro outra explicação possível, se não a manutenção do "pessimismo racial" que nos acompanha desde o século XIX ("a apatia, indolência e impudência do populacho negro"), para entender a retenção tão precoce de crianças negras na educação pré-escolar. Aposta-se, de antemão, que tal criança terá problemas no ensino fundamental.

Assume-se, pois, neste estudo, que a educação infantil tal como vem sendo implantada no país, constitui um dos mecanismos sociais, entre outros, que "coloca a população negra em desvantagem no processo competitivo de mobilidade social" (Hasenbalg, 1992.

19. A implantação da Lei do Fundo de Manutenção e Desenvolvimento do Ensino e Valorização do Magistério FUNDEF - prenuncia uma nova "depuração": a passagem de leigos do ensino fundamental para a educação infantil e uma transferência inversa de docentes qualificados(as) da educação infantil para o ensino fundamental. O monitoramento, nesse caso, é indispensável. 
p.57). E mais: as análises apontam que ocorreu um exacerbamento desse processo no bojo da implantação de uma política educacional para todos, baseada no argumento da equalização de oportunidades: para os pobres (compensação de carência), para as mulheres (a educação infantil como alternativa de guarda do filho, permitindo o trabalho materno). E o paradoxal é que, em todos os estados que implantaram e mantiveram esse modelo de educação infantil a baixo investimento, as Constituições Estaduais estampam pronunciamentos anti-racistas e anti-sexistas no capítulo da educação.

Recorrendo novamente a Petitat (1994), não se pode refletir sobre a democratização e melhoria do ensino fundamental sem analisar o que vem ocorrendo com a educação infantil e secundária ${ }^{20}$; não se pode pensar na movimentação das hierarquias educacionais, sem refletir sobre as movimentações nas hierarquias sociais de um modo geral| ${ }^{2 !}$.

É neste caminho que se seguem as implicações para superação dessas desigualdades. Diante das distorções aqui anunciadas na oferta de educação infantil, apareceram algumas sugestões para que se proíba, por norma ou outro ato legislativo, a permanência de crianças tendo sete anos e mais no pré-escolar. Isso seria reenfatizar a necessidade do respeito à Constituição. Tal medida porém não é suficiente, pois a exclusão se travestiria com outra roupagem. Ao invés de pré-escolar, ou classe de alfabetização, facilmente se criariam novos programas para reter, manter, separar segmentos excluídos de crianças em patamares educacionais inferiores ou em experiências educacionais de pior qualidade (classes de aceleração, por exemplo $)^{22}$ sob a responsabilidade de segmentos excluídos de mulheres. Enquanto creche valer menos que pré-escola, que vale menos que ensino fundamental, outras alternativas de exclusão serão criadas ou recriadas sobretudo se continuarmos contando com educadoras/professoras que não completaram a escolaridade básica e que, por isso, recebem salários inferiores aos previstos para professores diplomados. Daí a proposta política de investimento prioritário na formação básica e profissional das educadoras infantis.

Retomo então para concluir, a proposta de Willian Julius Wilson (1987) para políticas públicas destinadas à população negra pobre norte-americana - posição também defendida por Carlos Hasenbalg ( 1992) no Brasil: necessitamos de políticas não sexualmente ou racialmente específicas mas daquelas que visem à diminuição das desigualdades econômicas e

20. A implantação da lei do FUNDEF terá, com certeza, implicações no perfil da educação infantil: índice de matrícula, faixa etária das crianças, formação/qualificação docente (Campos, 1999; UNDIME, 1999).

21. Apenas a título indicativo, seria necessário acompanhar o recente processo de extinção das classes especiais (decorrente do movimento de integração das crianças consideradas como portadoras de necessidades especiais) e o aumento de matrículas de crianças com sete anos e mais na educação infantil. Isto é, supõe-se o impacto de outro aspecto da dinâmica social assinalada por Petitat (1994).

22. O perfil sociodemográfico (especialmente sexo e raça) da clientela das classes de aceleração poderia indicar a ocorrência, ou não, de "reacomodação" dessas crianças no sistema. Além disso, a análise de sua trajetória escolar pregressa (nos estados que apresentam "reprovação" no pré-escolar) poderia indicar se os(as) alunos(as) das classes de aceleração apresentam, ou não, uma escolaridade heterodoxa: retidos no pré-escolar e "acelerados" no ensino fundamental. 
educacionais. No caso da educação infantil, uma política de equalização de oportunidades para crianças brancas e negras significa equalização do padrão de qualidade (ou pelo menos redução drástica das diferenças atuais) o que passa, hoje, pela formação educacional dos(as) docentes que educam e cuidam de crianças pequenas em creches e pré-escolas. Afinal, essas instituições são espaços para educação das crianças e de trabalho para as mulheres.

\section{REFERÊNCIAS BIBLIOGRÁFICAS}

AMANN, S.B. Ideologia do desenvolvimento de comunidade no Brasil. São Paulo: Cortez, 1982.

BANCO MUNDIAL. Estudo sobre o desenvo/vimento infantil no Brasil. PRELIMINARES. s/: s.c.p. 1999. (mimeo.)

. Reunião do grupo consultivo sobre o estudo do desenvo/vimento infantil. Brasília, 1998. (mimeo.)

BARCELOS, L. C. Educação e desigualdades raciais no Brasil. Cadernos de Pesquisa. São Paulo, n.86, p.15-24, ago. 1993.

BARROSO, C. Mulher, sociedade e estado no Brasil. São Paulo: UNICEF; Brasiliense, 1982.

BAUDELOT, C., ESTABLET, R. Allez les filles. Paris: Seuil, 1992.

BEATTY, B. Child gardenig: the theaching of young children in American schools. In: WARREN, D. (ed). American teachers. histories of a profession at work. New. York: Mac Millan, 1989. p.65-97.

BELO HORIZONTE. Secretaria de Desenvolvimento Social. Diagnóstico da rede de creches conveniadas com a Secretaria de Desenvo/vimento Social. Belo Horizonte: MEC/RHIP, I 993.

BEMFAM. Pesquisa nacional sobre demografia e saúde /996. Rio de Janeiro, BEMFAM, 1997.

BLACK, M. The Children and the Nations, the story of UNICEF. Sidney: P.I.C. Pty Ltda., Potts Point 1986.

BRASIL. Departamento Nacional da Criança. Divisão de Proteção Social. Sugestões para um plano de assistência ao pré-escolar. s.I., 1967.

BRASIL. Ministério da Educação. A Educação no Brasil na década de 80. Brasília: MEC/SAG/ CGPS/CIP, 1990.

BRASIL. Ministério da Educação e Cultura. Dados pré-escolar, $1^{\circ}$ e $2^{\circ}$ graus - estimativas 1984-86. Brasília: MEC/SG/SEEC, I985c.

. Educação pré-escolar: uma nova perspectiva nacional. Brasília: MEC, 1975.

. Indicadores educacionais 1982//983. Brasília: MEC/SG/SI/SEEC, junho 1985. 
. Retrato do Brasil. Educação. Cultura. Desportos 1970- 1990. V. I. Brasília: MEC/ SG/SAEP, $1985 b$.

. Sinopse estatística da educação básica 1979//980. Brasília: MEC/SG/SI/SEEC, 1983.

. Sinopse estatística da educação básica 198///982//983. Brasília: MEC/SG/SI/ SEEC, 1984.

. Sinopse estatística da educação fundamental 1993. Brasília: MEC/SAG/CPS/ SEEC. 1994.

. Sinopse estatística da educação pré-escolar 76/78. Brasília: MEC/SG/SI/SEEC, 1981 .

. Sinopse da educação pré-escolar 1984. Brasília: MEC/SG/SEEC, 1986.

- Sinopse estatística de classes de alfabetização e educação pré-escolar. Censo Educacional 1992. Brasília: MEC/SAG/CPS/CIP, 1994.

- Sinopse estatística de classes de alfabetização e educação pré-escolar 1991. Brasília: MEC/SAG/CPS/SEEC, julho, 1994.

. Sinopse estatística de classes de alfabetização e educação pré-escolar 1992. Brasília: MEC/SAG/CPS/CIP, 1994.

. Sinopse estatística do ensino de pré- / grau - 69/75. Brasília: Departamento de Documentação e Divulgação, 1977.

- Subsídios para credenciamento e funcionamento de instituições de educação infantil. Brasília: MEC/SEF/DPEF, 1998.

BRASIL. Ministério da Educação e do Desporto. Instituto Nacional de Estudos e Pesquisas Educacionais. Censo escolar 1996. Brasilia: INEP, 1997.

. Censo escolar 1997. Brasília: INEP, 1998.

. Censo do professor. 1997. Brasília: MEC/NEP, 1998. (versão preliminar)

- Informe estatístico da educação básica: evolução recente das estatísticas da educação básica no Brasil. [http://www.inep.gov.br em 17/9/98]

. Sinopse estatística 1996. Brasília: INEP. 1997.

CAMPOS. M. M. Depoimento à comissão de educação da Câmara Federal. Brasília: FCC/ ANPED, 1999. (mimeo.)

CENTRO DE CULTURA LUIZ FREIRE. Grupo Alternativas Educacionais. Uma Estratégia de sobrevivência na região metropolitana do Recife. Olinda: CCLF, 1994.

CERIZARA, A. B. Formação de professores em serviço para a educação infantil: uma possível contribuição da universidade. Florianópolis: UFSC, 1995. 
CIVILETTI, M. V. P. O Cuidado às crianças pequenas no Brasil escravista. Cadernos de Pesquisa, São Paulo, n. 91, p. 3 I-40, fev. 1991.

COCHRAN, M. International handbook on child care policies and programs. Westport: Greenwood Press, 1993.

EGGER, C. Principales orientations de la politique de I'UNICEF: 1947-1979. S.I., 1985. [Texte prononcé au Colloque de Varsovie.] (mimeo.)

ENGUITA, M. Os desiguais resultados das políticas igualitárias nas perspectivas de classe, gênero e etnia na educação. Revista Brasileira de Educação. São Paulo: n.3, p.5-17, set./out./nov./dez. 1996.

. A Face oculta da escola. Porto Alegre: Artes Médicas, 1989.

FAURE, E. Apprendre à être. Paris:Fayard and UNESCO, 1972. (Le Monde Sans Frontières).

FERRARI, A. Evolução da educação pré-escolar no Brasil no período de 1968 a 1986. Revista Brasileira de Estudos Pedagógicos, v.69, n. 161 , p.55-74, abr. 1988.

. Pré-escola para salvar a escola? Educação e Sociedade, São Paulo, v. 4, n. 12 , p.29-37, set. 1982.

FRANCO, M. A C. Lidando pobremente com a pobreza. In: ROSEMBERG, F. (org.). Creche. São Paulo: Cortez; FCC, 1989. p.179-216.

FUNDAÇÃO INSTITUTO BRASILEIRO DE GEOGRAFIA E ESTATÍSTICA. Anuário estatístico do Brasil 1996. Rio de Janeiro: IBGE, 1997.

. Anuário Estatístico do Brasil 1994. Rio de Janeiro: IBGE, 1994.

. Pesquisa Nacional por Amostra de Domicílios - 1990. Rio de Janeiro: FIBGE, 1996.

. Pesquisa Nacional por Amostra de Domicilios - 1987. Cor da população v. I Brasil e Grandes Regiões. Rio de Janeiro: IBGE, 1989.

. Pesquisa Nacional por Amostra de Domicilios - 1995. Rio de Janeiro: FIBGE, 1997.

. Pesquisa Nacional por Amostra de Domicilios - 1996. Rio de Janeiro: FIBGE, 1997.

HASENBALG, C. A. Desigualdades raciais no Brasil. In: HASENBALG, C., SILVA, N. do V. Estrutura Social, mobilidade e raça. São Paulo: Vértice, I988, p. I I 5-43.

. Discriminação e desigualdades raciais no Brasil. Rio de Janeiro: Graal, 1979.

. 1976: as desigualdades raciais revisitadas. In: Movimentos sociais urbanos, minorias étnicas e outros estudos. Brasília, ANPOCS, 1983. p. 179-97. (Ciências Sociais Hoje, 2). 
. Notas sobre as relações de raça no Brasil e na América Latina. In: HOLLANDA, H. B. (org.). Y nosotras latino-americanas? Estudos sobre gênero e raça. São Paulo: F. Memorial da América Latina, 1992. p.52-8.

HICKS, E. Cultural marxism: non synchrony and feminist practice. In: SARGENT, L. Women and revolution. Boston: South and Press, 1981. p. 219-38.

IZQUIERDO, M. J. El Concepto de género. In: VILANOVA, M. (comp.). Pensar las diferencias. Barcelona: Universitat de Barcelona, 1991. p. 35-43.

JENSEN, J. J. Men in child care services. a discussion paper. Ravena, 1993. (mimeo).

KRAMER, S. A Política do pré-escolar no Brasil: a arte do disfarce. 5ed. São Paulo: Cortez, 1995.

LIMA, M. F. Atendimento pobre para o pobre: A L.B.A. em Mato Grosso do Sul. São Paulo, 1994. Dissert. (mestr.) PUC.

MELO, R. M. F. Avaliação dos programas municipais de educação pré-escolar conveniados com a secretaria de Educação: relatório de pesquisa. Boletim do CEPE, Florianópolis, v.17, n.2, p.14-32, abr./jun. 1984.

MYERS, R. A Brief History. Nova York: Consultative Group on early Childhood Care and Development, s/d. (mimeo)

PETITAT, A. Educação infantil na comunidade européia. In: BARRETO, A. M. R. F., OLIVEIRA, S. M. (org.). SIMPÓSIO NACIONAL DE EDUCAÇÃO INFANTIL, I. Anais. Brasília: MEC, 1995. p.157-64.

- Produção da escola/produção da sociedade: análise sócio-histórica de alguns momentos decisivos da evolução escolar no ocidente. Porto Alegre: Artes Médicas, 1994.

PNUD/PEA. Relatório sobre o desenvolvimento humano no Brasil. Rio de Janeiro: IPEA; Brasília: PNUD, 1996.

ROSEMBERG, F. A Criação de filhos pequenos: tendências e ambigüidades contemporâneas. In: RIBEIRO, I., RIBEIRO, A C. T. Família em processos contemporâneos: inovações culturais na sociedade brasileira. Rio de Janeiro: Loyola, 1995. p. 167-90.

. A Educação de mulheres jovens e adultas no Brasil. In: SAFFIOTI, H., MUÑOZVARGAS, M. Mulher brasileira é assim. Rio de Janeiro: Rosa dos Tempos, Nipas; Brasília: UNICEF, 1994. p.27-62.

. Creches domiciliares: argumentos ou falácias. Cadernos de Pesquisa, São Paulo, n.56, p.73-8I, fev. 1986.

. Educação infantil e processos de exclusão. São Paulo: FCC; Fapesp, I997a. (Relatório de Pesquisa). 
- Estado dos dados para avaliar políticas de educação infantil. Estudos e Avaliação Educacional, São Paulo, n.20, jul.-dez. 1999.

. A História da educação infantil na UNESCO. São Paulo: FCC; Fapesp, 1998. (Relatório de pesquisa).

. A L.B.A., o projeto casulo e a doutrina de segurança nacional. In: FREITAS, M. C. (org.). História social da infância no Brasil. São Paulo: Cortez; USF, 1997b, p. I37-58.

ROSEMBERG, F., PINTO, R. P. A Criança negra na PNAD 87. São Paulo: FCC, 1997. (Textos FCC n. 13).

. É de pequeno que se torce o pepino: criança negra, casa e escola; relatório. São Paulo: FCC/FAPESP, 1994. (Relatório de pesquisa).

ROSEMBERG, F. et. al. Diagnóstico sobre a situação educacional de negros (pretos e pardos) no Estado de São Paulo. São Paulo: Fundação Carlos Chagas, 1986. 2v.

. A Educação da mulher. São Paulo: Nobel, CECF, 1985.

. A educação da mulher no Brasil. São Paulo: Global, 1982.

SAPAROLLI, L. Educador infantil: uma ocupação de gênero feminino. São Paulo, 1997. Dissert. (mestr.) PUC/SP.

SCHLESINGER, J. As Novas prioridades do Mobral. Educação, Brasília, v. I 0, n.35, p.24-7, ago./out. 1981 .

SERPA, M. do C. V. Atendimento ao pré-escolar carente: utopia ou realidade? Diagnóstico da situação em movimento comunitários da Grande Vitória. Vitória, 1982. Dissert. (mestr.) Faculdade de Educação - UFES.

SILVA, W. A da. Influência da pré-escola no processo de alfabetização: um estudo de tendências e alternativas da pré-escola pública de Aracaju, 1986-1991. Aracaju: UFS, Departamento de Educação, Núcleo de Estudos e Pesquisas em Alfabetização, 1991.

SKIDMORE, T. E. Fato e mito: descobrindo um problema racial no Brasil. Cadernos de Pesquisa. São Paulo, n.79, p.5-16, nov.1991.

UNDIME. O Fundef na avaliação da Undime. Brasília. 1999.

UNESCO. 40 ans de solidarité entre les nations. Paris, UNESCO, 1988.

UNESCO. Rapport mondial surl'éducation. Paris, UNESCO, 1991.

. Statistical annuaire 1992. France: UNESCO, 1992

. XXVI Conférence Internationale de L'Instrution Publique. Paris, 1961. 
UNICEF. Infância e juventude no desenvo/vimento nacional na América Latina. Rio de Janeiro: UNICEF, FUNABEM, 1968.

VILARINHO, L. R. G. A Educação pré-escolar no mundo ocidental e no Brasil: perspectivas histórica e crítico - pedagogia. Rio de Janeiro, 1987. Tese (dout.) UFRJ.

WILSON, W. J. The truly disadvantaged. The inner city, the underclass, and public policy. London/Chicago: The University of Chicago Press, 1987. 